\title{
Uma análise do uso de métodos de planejamento e controle em operações de serviços de hospedagem em uma cidade histórica
}

\section{An analysis of the use of planning and control methods in operations of hosting services in a historical city}

\author{
Bruna Mendes Morais Bacharel em Engenharia de Produção. Universidade Federal de Ouro Preto (UFOP) - Brasil. \\ https://orcid.org/0000-0001-8833-7393 brunamendesmorais@yahoo.com.br \\ Irce Fernandes G. Guimarães Doutora em Engenharia de Produção. Universidade Federal de Ouro Preto (UFOP) - Brasil. \\ https://orcid.org/0000-0002-6530-9434 Irce@ufop.edu.br
}

\section{RESUMO}

Este artigo apresenta os resultados de uma análise do planejamento e controle das operações de serviços no setor hoteleiro de uma cidade histórica. Tradicionalmente, os estudos sobre a aplicação do Planejamento e Controle são voltados ao setor industrial. Porém, a importante participação da prestação de serviços na economia viabiliza a abordagem deste tema. Uma cidade histórica de Minas Gerais foi escolhida como foco deste estudo por fazer parte do roteiro turístico do país e por mostrar-se uma boa fonte para pesquisa. Esta análise teve caráter exploratório embasado na literatura de operação e planejamento de serviços. O referencial teórico inicia-se com a definição de serviços, seguida da caracterização do setor hoteleiro. Também, são abordadas a relevância da prestação de serviços para a economia e a percepção da qualidade neste setor. Apresenta-se ainda o conceito e as principais características do planejamento em serviços hoteleiros. Uma análise qualitativa foi utilizada por meio da elaboração e aplicação de um questionário acerca da gestão das operações, o que possibilitou a coleta de informações necessárias para a análise do planejamento e controle de serviços nos meios de hospedagem de uma cidade histórica. Os resultados evidenciam a necessidade de maior investimento no preparo e treinamento dos funcionários e de outros serviços que, juntamente com a hospedagem, constituiriam a cadeia de suprimentos do setor hoteleiro da região. O planejamento estratégico é uma das carências observadas nos meios de hospedagem analisados, bem como, a necessidade de planejamentos para a capacidade ociosa em períodos de baixa temporada.

Palavras-chave: planejamento e controle de operação de serviços; gestão de serviços; setor hoteleiro; qualidade.

\begin{abstract}
This article presents the results of an analysis of the planning and controlling of the service operations in the hotel industry of a historical city. Studies on the application of Planning and Controlling have traditionally focused on the industrial sector. However, provision of services has a high economic and social importance and must be regarded. A historical city in the state of Minas Gerais was chosen for its relevance in a meaningful tourist route in Brazil. This analysis has an exploratory nature based on the literature of operation and service planning. The theoretical framework begins with the definition of services, followed by the characterization of the hotel industry. Relevance of the provision of services to the economy and the perception of quality in this sector are addressed. The concept and the main characteristics of planning in hotel services are also presented. A qualitative analysis was used by way of a tailored and applied questionnaire about operation management. Thereby it was possible to gather the main information for the analysis of service planning and controlling in the hotel industry of a historical city. The results pointed out the need for higher investment on the staff training as well as on the hospitality service chain of the region. Poor strategic planning and arrangements in the analyzed lodging facilities, as well as their idle capacity in low season were also noticed in this research.
\end{abstract}

Keywords: planning and controlling of service operations; service management; hotel industry; quality. 


\section{INTRODUÇÃO}

As mudanças que ocorrem no setor terciário, principalmente aquelas relacionadas a aspectos econômicos, tecnológicos, políticos, ambientais e culturais, configuram um novo cenário de incertezas e imprevisibilidade para as organizações. Este fato impõe a necessidade de evolução nos processos gerenciais, a fim de obter a primazia na prestação de serviços e, por conseguinte, garantir a sobrevivência em um cenário de crescentes mudanças que vem tornando cada vez mais relevante na economia mundial.

Lustosa, Mesquita \& Quelhas (2008), destacam que "O aumento da circulação de informações, o avanço das tecnologias disponíveis e a necessidade, cada vez mais crescente, de usufruir de maior conforto e qualidade de vida, tem impulsionado o mundo à utilização cada vez maior da indústria de serviços".

No Brasil, a mesma tendência é observada, ainda que haja diferenças no perfil de consumo do brasileiro em função da distribuição desigual de renda. O maior acesso à informação leva a população a prezar, cada vez mais, pela qualidade na prestação de serviços e, estudos apontam que, em muitos momentos da economia, o consumidor se mostra disposto a renunciar o consumo de um produto para adquirir um serviço, como por exemplo, saúde e educação.

O Instituto Brasileiro de Geografia e Estatística - IBGE (2018), por meio da Pesquisa Anual de Serviços (PAS), confirma a existência de cerca de 1,3 milhões de empresas ativas que têm sua principal atividade exercida no âmbito do setor de serviços não financeiros. Em 2018, essas empresas totalizaram R\$ 1,6 trilhão em receita operacional líquida, empregaram por volta de 12,6 milhões de trabalhadores e pagaram uma quantia estimada em $\mathrm{R} \$ 353,4$ bilhões de reais em salários, retiradas e outras remunerações.

De acordo com mapeamento de HOSPITALITY GROUP (2019), existe uma imprecisão em relação ao número de hotéis no Brasil, porém, estima-se que até o ano de 2019 cerca de 10.501 empreendimentos hoteleiros foram encontrados nos sites especializados de informações de mercado no país. Esses empreendimentos podem ser classificados em quatro grupos: Hotéis e flats de marcas nacionais (668), Hotéis e flats de marcas internacionais (607), Hotéis independentes com até 20 quartos (3724) e hotéis independentes com mais de 20 quartos (5502). A concentração de hóspedes encontra-se, em grande maioria, nos hotéis urbanos e, segundo dados do Ministério do Turismo (2020), o setor de turismo absorveu, em 2019, aproximadamente 35.692 novos postos de trabalhos com aumento de 3,3 \% na utilização dos serviços de hospedagem em relação ao ano anterior. Houve, também, mais de 31 mil empregos diretos e uma movimentação de, aproximadamente, $R \$ 238,6$ bilhões na economia.

Uma vez observado a participação dos serviços hoteleiros no cenário brasileiro e, o fato dos clientes prezarem, cada vez mais, pela eficiência neste setor, surge, então, a questão sobre como é realizado o planejamento desses serviços.

Soltani et al. (2012) reiteram que existe alta taxa de falha na execução das operações de serviço e reconhece que a qualidade e o planejamento das operações são fatores importantes quanto à expectativa e percepção do cliente. Neste sentido, observa-se que o conceito de planejamento e controle aplicado ao setor de serviços, tem despertado o interesse de pesquisadores, uma vez que, tradicionalmente, os conceitos clássicos do Planejamento e Controle da Produção (PCP) eram empregados, na maioria das vezes, na produção de bens manufaturados.

Desta forma, neste artigo apresentam-se os resultados de uma pesquisa sobre a adequação dos conceitos do planejamento e controle da produção ao setor de serviços. Também são sinalizadas as atividades já implantadas nos serviços hoteleiros de uma cidade histórica e algumas sugestões para aprimorar o planejamento e controle. Os resultados da pesquisa estão descritos, neste artigo, da seguinte forma: nas seções 2 e 3, apresenta-se uma breve descrição do setor de serviço, economia, qualidade e tecnologia no setor de serviços, comparativo entre PCP na manufatura e em serviços e caracterização do setor hoteleiro. Nas seções 4 e 5 são apresentados o método utilizado para esta pesquisa e os resultados com as principais análises. Por fim, na seção 6, descreve-se as considerações finais e sugestões para trabalhos futuros.

\section{O SETOR DE SERVIÇOS}

Os serviços estão presentes em toda a cadeia produtiva, a começar dos fornecedores até o cliente final. A definição de serviço é muito diversificada e, algumas, como as apresentadas a seguir, apontam para a importância do cliente como elemento fundamental das operações de serviços. 


\begin{tabular}{|c|l|}
\hline Autor (ano) & \multicolumn{1}{|c|}{ Definições } \\
\hline Kotler (1998) & $\begin{array}{l}\text { São atos ou desempenho que uma parte oferece a outra de forma que seja } \\
\text { totalmente intangível e não resulte em propriedade de nada. }\end{array}$ \\
\hline Bowen \& Ford (2002) & $\begin{array}{l}\text { Atividade intangível que inclui elementos que são responsáveis por criar } \\
\text { uma experiência memorável para o cliente em um determinado intervalo } \\
\text { de tempo. }\end{array}$ \\
\hline Vargo \& Lusch (2004) & $\begin{array}{l}\text { Habilidades e conhecimentos especializados aplicados por meio de ações, } \\
\text { processos ou atuações para benefício próprio, de uma pessoa ou de uma } \\
\text { entidade. }\end{array}$ \\
\hline $\begin{array}{c}\text { Lovelock,Wirtz e Henzo, } \\
(2011)\end{array}$ & $\begin{array}{l}\text { Atividade econômica oferecida a terceiros, geralmente são intangíveis e } \\
\text { traz aos seus clientes os resultados desejados. }\end{array}$ \\
\hline Zeithaml, Mary, Dwayne & $\begin{array}{l}\text { São atos, processos ou atuações oferecidos ou coproduzido por uma } \\
\text { entidade ou pessoas para outras pessoas ou entidades. }\end{array}$ \\
\hline Pereira (2019) & $\begin{array}{l}\text { Processo de realização de um trabalho para satisfazer a necessidade de um } \\
\text { consumidor cujo resultado poderá ser tangível ou intangível. }\end{array}$ \\
\hline
\end{tabular}

As principais características dos serviços, apresentadas nas definições podem ser visualizadas nos serviços de reparo e manutenção, alimentação, hotelaria, transportes, seguros, comércio, finanças, serviços legais, serviços médicos, entretenimento e outros. Desta maneira, Heizer e Render (2001), organizam, como na Figura 1, as principais características dos serviços.

\begin{tabular}{|c|c|}
\hline Serviços são intangíveis & $\begin{array}{l}\text { - Experiências vivenciadas pelos clientes na hora da prestação } \\
\text { do serviço. Exemplo: reserva de um quarto de hotel. }\end{array}$ \\
\hline $\begin{array}{l}\text { Serviços são consumidos } \\
\text { simultaneamente }\end{array}$ & $\begin{array}{l}\text { - Não existe armazenamento ou estoque de serviços. Exemplo } \\
\text { - uma apresentação teatral que ao ser apresentada ao } \\
\text { mesmo tempo é assistida pela plateia. }\end{array}$ \\
\hline $\begin{array}{l}\text { Serviços têm alta interação com } \\
\text { o cliente }\end{array}$ & $\begin{array}{l}\text { - Os serviços exclusivos pelos quais o cliente paga um valor } \\
\text { maior. Exemplo - os serviços de tv a cabo }\end{array}$ \\
\hline $\begin{array}{l}\text { Serviços muitas vezes são } \\
\text { baseados no conhecimento }\end{array}$ & $\begin{array}{l}\text { - Geralmente não possibilitam automatização. Exemplo: } \\
\text { Serviços educacionais e de consultoria }\end{array}$ \\
\hline Serviços muitas vezes são únicos & - Serviços personalizados. Exemplo: atendimento psicológico. \\
\hline Serviços são dispersos & $\begin{array}{l}\text { - Conseguem alcançar os clientes nos mais diversos locais. } \\
\text { Exemplos: Serviço de telefonia e internet. }\end{array}$ \\
\hline
\end{tabular}

Figura 1. Principais características dos serviços

Fonte: Adaptação de Heizer e Render (2001)

Fitzsimmons e Fitzsimmons (2000) afirmam que existe uma correlação forte entre a compra de um serviço e de um produto, ou seja, quando um produto é adquirido, o cliente também recebe algum tipo de serviço de apoio. Por outro lado, quando se compra um serviço, produtos manufaturados também podem ser usufruídos conjuntamente. Este fato é considerado na precificação de alguns serviços aliados às atividades de manufatura, visando atender às estratégias de gestão das atividades que agregam valor aos resultados das organizações. Neste sentido, é importante entender qual é a proporção entre bens e serviços, pelo fato de um serviço ser uma atividade que agrega valor aos resultados e experiências entregues aos clientes. Essas operações, de acordo com Gianesi \& Correa (1994), estão separadas em atividades visíveis e não visíveis para o cliente. Na Figura 2 é apresentada a proporção entre bens e serviços de um sistema produtivo. 


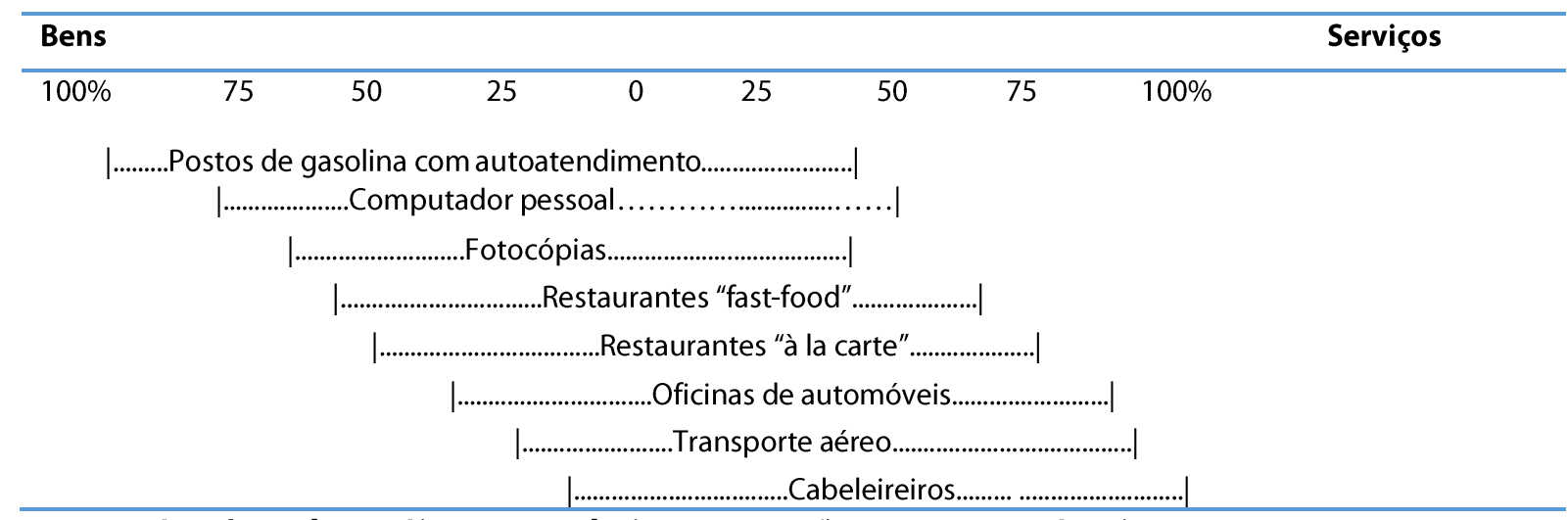

Figura 1. Contínuo de um Sistema Produtivo: Proporção entre Bens e Serviços

Fonte: Fitzsimmons e Fitzsimmons (2000)

Outra divisão para as operações de serviços é apresentada por Johnston \& Clark (2002). Segundo estes autores, as operações de serviços podem ser divididas em duas partes:

- Front office: alto contato com o cliente, a experiência do cliente é significativa, alto grau de incerteza, alta variabilidade, difícil controle e maior valor agregado na linha de frente.

- Back room: baixo contato com o cliente, a experiência com o cliente é mínima, existe maior previsibilidade e padronização, maior facilidade de controle e maior valor agregado na retaguarda.

Segundo Gianesi \& Correa (1994), os serviços podem ser diferenciados em relação aos aspectos que mais interferem na gestão dos serviços, são eles: o grau de customização dos serviços, grau de participação do cliente nas operações e a intensidade de contato com o cliente. Outra classificação é apresentada por Brito e Santos (2019), para eles os serviços podem ser classificados em três categorias básicas: Serviços Profissionais, Loja de Serviços e Serviços de Massa, conforme pode ser visualizado na Figura 3.
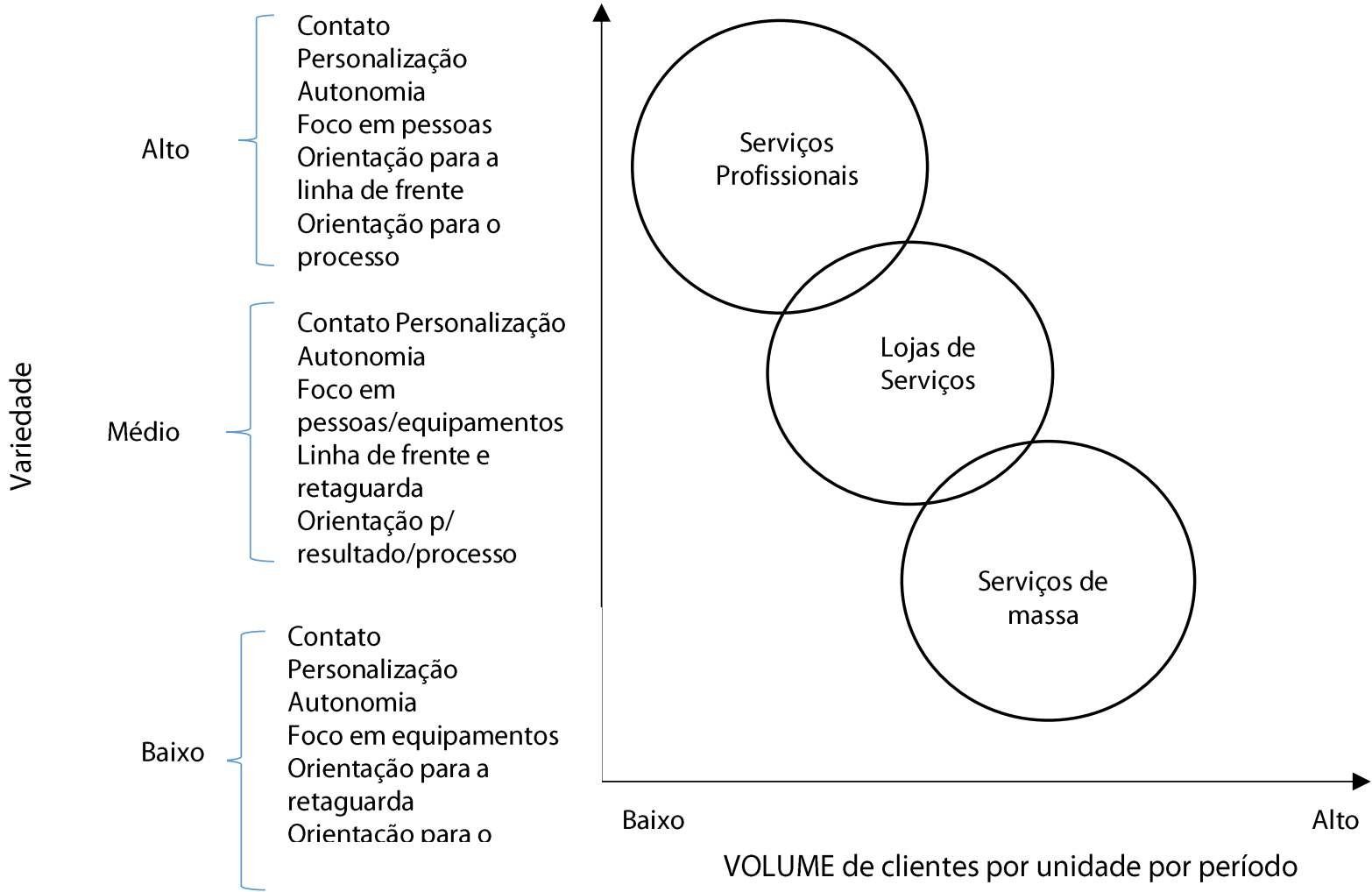

Figura 2. Classificação de serviços

Fonte: Brito e Santos (2019) 


\subsection{Economia, tecnologia e qualidade no setor de serviços}

Para Moreira (2017), os serviços acompanham os ciclos econômicos, uma vez que o consumo dos serviços está diretamente ligado à renda e a atividade econômica. As atividades de serviços na sociedade brasileira exercem relativa importância na economia pois influenciam tanto o Produto Interno Bruto (PIB), quanto a geração de emprego e renda. De acordo com dados do Ministério da Indústria Comércio Exterior e Serviços (2017), entre os anos de 2003 a 2015, a participação do setor de serviços no PIB brasileiro aumentou cerca de 7\%, passando de 65,8\% para 72,8\% do valor adicionado. Já no período entre 2017 e 2018 , os resultados por setores não foram tão favoráveis, principalmente no setor de serviços que por representar mais de 70\% da economia, essa atividade fechou com resultado de contração de 0,6 \% ao final de 2018.

Ainda, o setor de serviços exerce importante participação em outros setores da economia. De acordo com o Ministério da Indústria Comércio Exterior e Serviços (2017), este setor contém os insumos determinantes para acelerar o crescimento econômico e a produtividade, pois são indispensáveis para melhorar a infraestrutura, a logística, o acesso e o uso das tecnologias da informação e comunicação, a educação e, também, a competitividade do setor de bens e manufaturas, pois como afirmam Fitzsimmons e Fitzsimmons (2000), cada compra é composta por bens e serviços em proporções distintas.

Deste modo, Moreira (2017) aponta a necessidade de desenvolver um setor de serviços qualificado e cada vez mais integrado às cadeias de produção, pois as mudanças do perfil de consumo e os avanços tecnológicos, apontam que o crescimento dos países no século XXI tende a ser cada vez mais baseado no setor de serviços.

"Como a tecnologia das máquinas em um dado momento transformou a economia agrária em economia industrial, também a tecnologia de informação hoje transforma nossa economia industrial em uma economia baseada em serviços" (Fitzsimmons \& Fitzsimmons, 2000). A tecnologia na gestão das operações de serviços tem contribuído significativamente para o crescimento do setor. Como já apontavam Rodrigues et al. (1986), existe uma tendência de industrialização dos serviços. Para os autores, a tecnologia possibilitou uma maior segmentação das operações, proporcionando maior eficiência no planejamento e controle dos processos, da mesma forma que acontecia na manufatura.

O papel da tecnologia e dos sistemas de informação na prestação de serviços é bastante relevante para o desenvolvimento do setor. As tecnologias permitem a integração entre os principais recursos empregados nas operações de serviços, facilitam a integração entre pessoas, informações e estruturas. A utilização das inovações tecnológicas possibilita aos gestores tomarem decisões mais assertivas e rápidas focadas às estratégias da organização, respeitando sempre os limites e a aceitação de seus clientes. Para Lustosa, Mesquita e Quelhas (2008), as vantagens da aplicação da tecnologia em serviços são o custo da tecnologia, cada vez mais barato, a padronização, a rapidez, a facilidade de uso, a confiabilidade e a conveniência que a tecnologia proporciona ao cliente.

Johnston \& Clark (2002) acreditam que a importância da tecnologia para a gestão das operações de serviços está no fato de que uma maior utilização da tecnologia tende a promover modificações na forma como as atividades são gerenciadas. Atividades de retaguarda, podem passar a ser executadas e fornecidas via Web, enquanto atividades da linha de frente, segundo Fitzsimmons e Fitzsimmons (2000), tendem a apresentar maior valor agregado quando aliadas à tecnologia. As informações obtidas durante o atendimento ao cliente possibilitam criar uma cadeia de valor virtual gerando informações úteis para o planejamento das operações e qualidade nos serviços.

De acordo com Avila e Avila (2001), em relação a serviços, o conceito de qualidade não pode ser medido somente por meio de objetivos, como ocorre nas industrias manufatureiras. A qualidade em serviço tem características específicas como a intangibilidade, nesse caso, o mais adequado seria analisá-la quanto a sua percepção pelo cliente. O julgamento do cliente quanto a qualidade dos serviços prestados se dá por meio da comparação, o serviço que lhe é entregue e a expectativa.

Alguns autores como Gianesi \& Correa (1994) e Johnston \& Clark (2002), defendem que a satisfação do cliente inclui, percepção, expectativa e resultados, assim, a qualidade de um serviço na avaliação do cliente, sofre influência direta da percepção e da expectativa do cliente. A Figura 4, destaca os pontos de atenção em relação a satisfação do cliente e da qualidade dos serviços. 


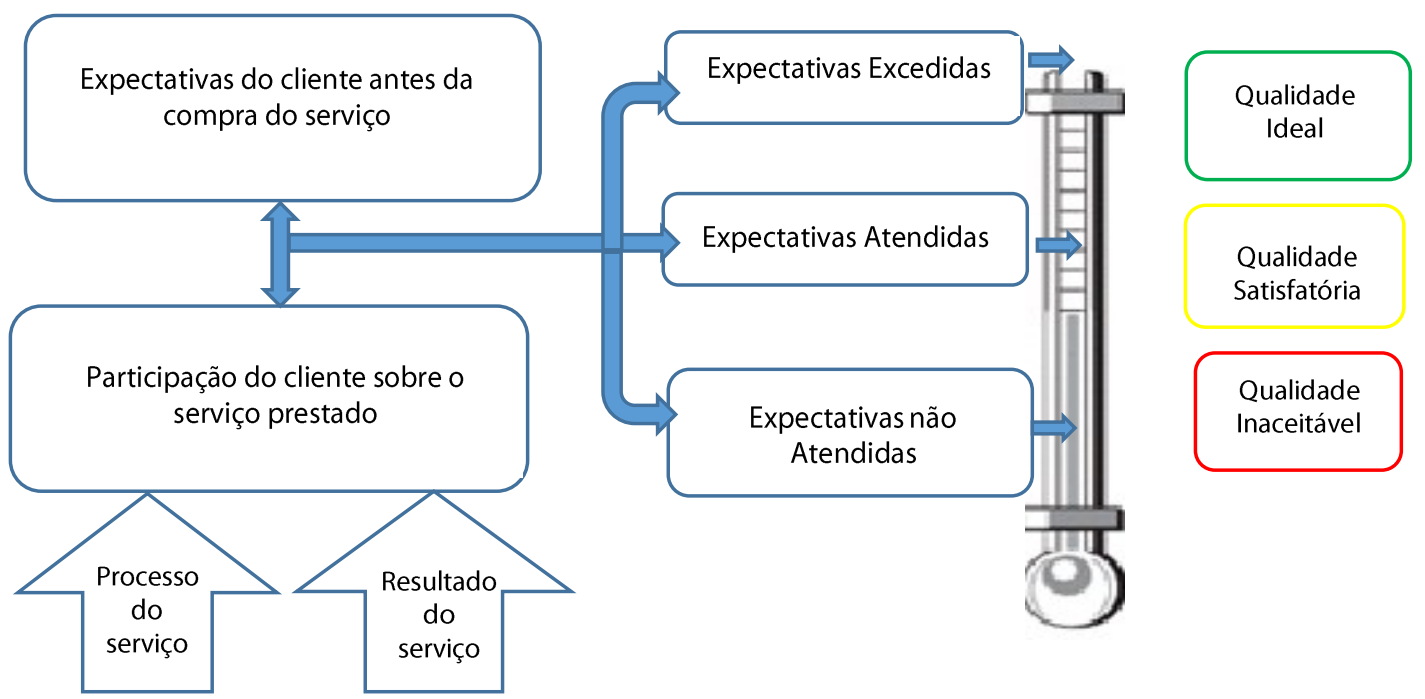

Figura 3. Satisfação do cliente e a qualidade dos serviços

Fonte: Gianesi e Correa, 1994 como referido em Guimarães (2010).

Mensurar a satisfação dos clientes apresenta benefícios tanto para a empresa prestadora do serviço quanto para o cliente. A qualidade dos serviços, porém, é mais difícil de mensurar do que a qualidade de um produto. Segundo Guimarães (2010), a qualidade dos serviços envolve a competição de mercado e a capacidade das empresas prestadoras de serviços em atender às necessidades dos clientes. Ainda, um serviço de qualidade transforma informações em conhecimento e conhecimento em tomada de decisão, que aliada a metodologias e estratégias de gestão proporcionam melhor planejamento e controle dos serviços.

\subsection{Planejamento e controle da produção aplicado em operação de serviços}

Os primeiros estudos sobre Planejamento e Controle da Produção (PCP) aplicados em serviços iniciaram-se por volta da década de 1970. Alguns pesquisadores a partir deste período têm adaptado os conceitos do planejamento e controle para produtos manufaturados e também desenvolvido novas abordagens para a aplicação em serviços, considerando o fato de o setor apresentar características específicas e elevado grau de intangibilidade e interação com o cliente.

Segundo Davis, Aquilano \& Chase (2001), muitos conceitos desenvolvidos inicialmente para a manufatura vêm sendo aplicados na gestão de serviços, porém ele alerta para o fato de que os gestores devem atentar-se para as características próprias dos serviços, o que tem levado ao surgimento de abordagens lógicas específicas para uma melhor execução do PCP em serviços.

Para Corrêa \& Corrêa (2008), conceitualmente, a gestão de operações de manufatura e de serviços não apresenta diferenças significativas. Segundo estes autores, ambas as operações passam pelos mesmos processos produtivos, porém o que muda entre um tipo de operação e outra é o que se gerencia em cada processo, o fluxo de processamento pode ser materiais a serem manufaturados, ou um fluxo de pessoas e informações, no caso dos serviços. Reforçando essa afirmação, Chase, Jacobe \& Aquilano (2006), explicam que as operações de serviços são muito similares às de manufatura, mas com algumas diferenças em relação ao foco dos processos, devido ao alto grau de personalização e contato com o cliente e, também à velocidade de entrega dos serviços. Desde 1998, Lemos \& Erdmann (1998) já afirmavam que o PCP poderia ser aplicado na indústria de serviços, mesmo havendo diferenças em alguns aspectos operacionais da indústria de produção de bens. Os mesmos autores lembram que o objetivo principal do PCP é operacionalizar uma empresa de maneira eficiente, por meio de planejamento, programação e controle das operações do processo produtivo.

Desta maneira, alguns estudiosos do tema abordam como conceitos do PCP são aplicados em serviços. É o caso de Heizer \& Render (2001). Estes autores defendem que grande parte dos custos e da qualidade de um serviço são definidos na etapa de projetos. Na manufatura também existem algumas técnicas que podem auxiliar na redução destes custos, como a customização do serviço, o mais tarde possível no processo, a modularização do produto para facilitar a personalização, focar no momento da venda onde ocorre maior interação com o cliente, dando-lhe atenção e melhorando a qualidade dos serviços.

Ainda segundo Heizer \& Render (2001), muitas empresas de serviços realizam o chamado planejamento agregado, um exemplo é o planejamento das necessidades de recursos humanos em relação a 
variabilidade da demanda, objetivando, desta maneira, uma melhor utilização dos recursos de mão-de-obra nos períodos de menor demanda. Neste contexto, alguns estudos sugerem uma abordagem de maneira contínua, ou complementar, da relação entre a produção de bens e a prestação de serviços. Bens e serviços são de certa forma complementares, portanto, o planejamento e o controle das operações de serviços e de manufatura seguem basicamente os mesmos princípios. Assim, segundo Davis, Aquilano e Chase (2001), em um "feixe" de manufatura e serviços, os bens seriam os resultados tangíveis de um processo e serviços os resultados intangíveis.

Outro fator que Costa (2017) sinaliza e que vem contribuindo para modificar a maneira como os bens e serviços são projetados, planejados e controlados pelas empresas são as influências da quarta revolução. A "internet das coisas", está mudando a forma de ver e lidar com os serviços. O avanço da inteligência artificial e do machine learning tendem a gerar produtos "servificados", ou seja, o consumidor não deseja mais apenas comprar um produto, ele importa cada vez mais com as experiências adquiridas com os serviços oferecidos.

Desta maneira, o PCP aplicado em serviços apresenta como foco os processos de linha de frente e a percepção do cliente, como propõem Santos, Varvakis e Gohr (2004) em um modelo conceitual de estratégias de operações para serviços respeitando suas características principais, como mencionadas anteriormente e, considerando, também, o conceito de serviços, o pacote de serviços e as estratégias da organização. De acordo com os autores, o modelo possibilitaria maior integração entre operações e marketing, além de melhorias do processo de formulação e implementação das estratégias de operações de serviços, por meio de um processo contínuo de aprendizagem e desenvolvimento de competências.

As atividades das operações de um processo de manufatura de bens e de serviços são baseadas em decisões de longo, médio e curto prazo. Ao comparar os dois processos observa-se relativa semelhanças e, algumas diferenças decorrentes das características bastante específicas dos serviços, que por serem intangíveis, não estocáveis, de consumo simultâneo e de elevada interação com o cliente levam a necessidade de mudança de foco do planejamento e controle das operações de serviços em relação às operações da manufatura. O comparativo do PCP na manufatura e em serviços, é apresentado no Quadro 1.

Ainda, é possível observar no Quadro 1, que a qualidade do produto ou serviço entregue ao cliente é apontada como principal semelhança do foco de planejamento e o controle das operações. A qualidade de um produto ou serviço está diretamente ligada à percepção do cliente, principalmente, no que diz respeito a prestação de serviços. Enquanto nas operações da manufatura, o cliente não participa diretamente do processo, o mesmo não ocorre nas operações de serviços, pois, nestas operações o cliente é parte integrante tanto do processo quanto dos resultados.

\begin{tabular}{|c|c|c|c|c|}
\hline PCP & $\begin{array}{l}\text { DECISÕES DE } \\
\text { LONGO PRAZO }\end{array}$ & $\begin{array}{l}\text { DECISÕES DE } \\
\text { MÉDIO PRAZO }\end{array}$ & DECISÕES DE CURTO PRAZO & FOCO \\
\hline 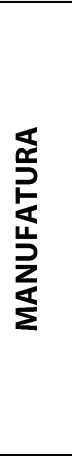 & $\begin{array}{l}\text { PLANEJAMENTO } \\
\text { ESTRATÉGICO - } \\
\text { Projeto do produto; } \\
\text { Definição do } \\
\text { processo; Previsão de } \\
\text { vendas e Previsão de } \\
\text { capacidade de } \\
\text { produção. } \\
\text { (Período acima de } 18 \\
\text { ou } 24 \text { meses) }\end{array}$ & $\begin{array}{l}\text { PLANEJAMENTO } \\
\text { MESTRE - } \\
\text { Previsão de } \\
\text { vendas de médio } \\
\text { prazo e } \\
\text { Planejamento da } \\
\text { capacidade } \\
\text { produtiva. } \\
\text { (Período de } 6 \text { a } \\
18 \text { meses) }\end{array}$ & $\begin{array}{l}\text { PROGRAMAÇÃO E CONTROLE- } \\
\text { Programação: Define as quantidades } \\
\text { a serem produzidas em cada } \\
\text { período; As necessidades de } \\
\text { materiais; Os prazos e as vendas. } \\
\text { Controle: Garantir que a } \\
\text { programação da produção seja } \\
\text { executada de acordo com o } \\
\text { planejado; Acompanhamento por } \\
\text { coleta e análise dos dados da } \\
\text { produção. } \\
\text { (Período de até } 6 \text { meses) }\end{array}$ & $\begin{array}{l}\text { Custo/Preço } \\
\text { Qualidade } \\
\text { Eficiência } \\
\text { Operações de retaguarda } \\
\text { Operações mais } \\
\text { padronizadas } \\
\text { Menor grau de incerteza } \\
\text { e variabilidade } \\
\text { Processamento de } \\
\text { produtos }\end{array}$ \\
\hline 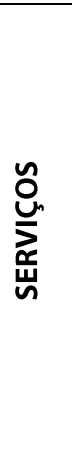 & $\begin{array}{l}\text { PLANEJAMENTO - Pr } \\
\text { Definição do process } \\
\text { quantidade. }\end{array}$ & $\begin{array}{l}\text { jeto do produto; } \\
\text { e Definição de }\end{array}$ & $\begin{array}{l}\text { PROGRAMAÇÃO E CONTROLE - } \\
\text { Programação: Definição dos } \\
\text { produtos; Definição dos produtos } \\
\text { complementares e materiais; Prazos } \\
\text { e capacidade do serviço. } \\
\text { Controle: Liberação e Controle do } \\
\text { serviço para que seja executado de } \\
\text { acordo com o planejado. } \\
\text { (Período determinado por cada tipo } \\
\text { de serviço) }\end{array}$ & $\begin{array}{l}\text { Qualidade } \\
\text { Rapidez } \\
\text { Eficiência } \\
\text { Personalização } \\
\text { Percepções e } \\
\text { expectativas do cliente } \\
\text { Operações de linha de } \\
\text { frente } \\
\text { Maior grau de incerteza e } \\
\text { variabilidade } \\
\text { Processamento de } \\
\text { pessoas }\end{array}$ \\
\hline
\end{tabular}

Quadro 1. Comparativo do PCP aplicado na manufatura e em serviços

Fonte: Elaborado pelas autoras (2019). 


\section{CARACTERIZAÇÃO DO SETOR HOTELEIRO}

Segundo Guasso (2009), não se sabe ao certo como a atividade hoteleira teve início, mas acredita-se que tenha surgido alguns anos antes da era cristã em função da necessidade natural que os viajantes tinham de abrigo, apoio e alimentação durante suas viagens. A construção das primeiras estradas feitas por gregos e romanos, promoveu uma evolução da hotelaria permitindo a construção de meios de hospedagem ao longo das estradas e este fato influenciou quase todos os países europeus. Desta forma, as antigas hospedarias construídas na época romana até a idade média passaram por diversas transformações até chegar ao modelo dos meios de hospedagem atuais.

O surgimento do setor hoteleiro no Brasil, de acordo com Knupp (2012), tem início entre o final do século XIX e início do século XX nas cidades de São Paulo e Rio de Janeiro, com significativo crescimento até o início da década de 1970. Neste período, a criação da Embratur, Instituto Brasileiro de Turismo, pertencente ao Ministério do Turismo, e do Fundo Gestor do Turismo (Fungetur), possibilitou o surgimento de programas de estímulo e financiamento do setor hoteleiro no país. Pereira \& Coutinho (2007) pontuaram que as redes hoteleiras internacionais, começaram a se instalar no Brasil entre as décadas de 1960 e 1970, promovendo mudanças nos padrões de preço e prestação dos serviços hoteleiro e, juntamente com as redes nacionais, contribuíram, significativamente, para o desenvolvimento turístico do país.

A classificação hoteleira no Brasil é definida pelo Instituto Brasileiro de Turismo - EMBRATUR, juntamente com o Instituto Nacional de Metrologia, Normalização e Qualidade Industrial - INMETRO e a Associação Brasileira da Indústria Hoteleira - ABIH de acordo com os padrões de instalações e serviços que apresentam (Figura 5). Portanto, de acordo coma classificação apresentada na Figura 5, se um meio de hospedagem oferece apenas o serviço de acomodação, este será classificado como simples. Um meio de hospedagem que oferece serviços para realização de eventos é classificado como um hotel do tipo superior. Dentre as categorias de classificação dos meios de hospedagem apresentadas na Figura 5, há ainda uma subdivisão. De acordo com Mello \& Goldenstein (2010), no Sistema Brasileiro de Classificação de Meios de Hospedagem, os meios de hospedagem são classificados em sete grupos diferentes: hotel, hotel histórico, hotel fazenda, resort, flat, pousada e cama e café.

\begin{tabular}{|c|c|}
\hline Categoria & Símbolo \\
\hline Super Luxo & 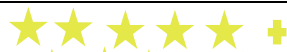 \\
\hline Luxo & $\star \star x+t+$ \\
\hline Superior & $t+t+$ \\
\hline Turístico & $x+x$ \\
\hline Econômico & txt \\
\hline Simples & 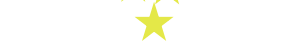 \\
\hline
\end{tabular}

Figura 4. Classificação dos meios de hospedagem no Brasil

Fonte: Turismo (2011)

De acordo com o Departamento Intersindical de Estatística e Estudos Socioeconômicos - Dieese (2013), o segmento hoteleiro é composto de hotéis, hospedarias e pousadas que prestam serviços, essencialmente, a turistas. O mercado doméstico de serviços hoteleiros apresenta algumas características importantes como: mercado pulverizado, pouca concorrência, sazonalidade e divisão entre o turismo de lazer e o turismo de negócios.

\subsection{Os serviços do setor hoteleiro}

Os serviços são definidos, geralmente, como atividades ou satisfações que são colocadas à venda. Desta forma, ao observar a classificação dos serviços apresentadas na Figura 3, é possível considerar que uma hospedagem pode ser classificada como loja de serviços. Uma hospedagem apresenta atividades de retaguarda e de linha de frente, tem alto grau de interação com o cliente e alto nível de transação, mas, por outro lado, buscam reduzir seus custos conforme o grau de customização dos serviços. Uma hospedagem foca tanto no processo quanto no produto final. Para Graeml et al. (2000), os serviços oferecidos por uma hospedagem, constituem o pacote de serviços, incluem todos as atividades entregues ao cliente sejam elas instalações de apoio, bens físicos facilitadores, serviços explícitos e serviços implícitos. De acordo com o Ministério do Turismo (2011), entende-se por meio de hospedagem: 
"Os empreendimentos ou estabelecimentos, independentemente de sua forma de constituição, destinados a prestar serviços de alojamento temporário, ofertados em unidades de frequência individual e de uso exclusivo do hóspede, bem como outros serviços necessários aos usuários, denominados de serviços de hospedagem, mediante a adoção de instrumento contratual, tácito ou expresso, e cobrança de diária." (Artigo 23 da Lei no 11.771/2008).

Portanto, é possível observar que o principal objetivo de uma hospedagem ou acomodação é na verdade oferecer um serviço. Os demais serviços fornecidos como alimentação, serviços de quarto, lavanderia, lazer, espaço para eventos entre outros, servirão como base para a classificação de uma hospedagem, de acordo com os serviços prestados. O ciclo de serviços de uma hospedagem não se encerra quando o cliente deixa a hospedagem. Há ainda, o serviço de pós venda, uma tentativa de fidelização do cliente, ou seja, quando há a percepção de um serviço que atenda ou supere as expectativas pode haver grandes chances de renovação ou retorno do cliente ao local.

Para Castelli (1992), a prestação dos serviços hoteleiros ocorre por meio de um processo de serviço, que deve ser muito bem planejado e controlado desde o momento em que o cliente solicita um serviço até sua execução, na forma de atendimento ao cliente. A gestão eficiente destes processos deve englobar um planejamento ordenado com a descrição das tarefas envolvidas na prestação dos serviços, assim como devem ser definidos local, fornecedores, tempo e qualidade dos serviços oferecidos pelos meios de hospedagem. Ainda, todo esse processo deve contar com uma boa infraestrutura e pessoas qualificadas para a prestação de serviço.

\subsection{Planejamento programação e controle das operações de serviços hoteleiros}

Klement (2000) e Lemos \& Erdmann (1998), em seus estudos sobre o planejamento e o controle da produção de serviços do setor hoteleiro, descrevem que o planejamento das operações de serviços hoteleiros envolve as etapas apresentados na Figura 6:

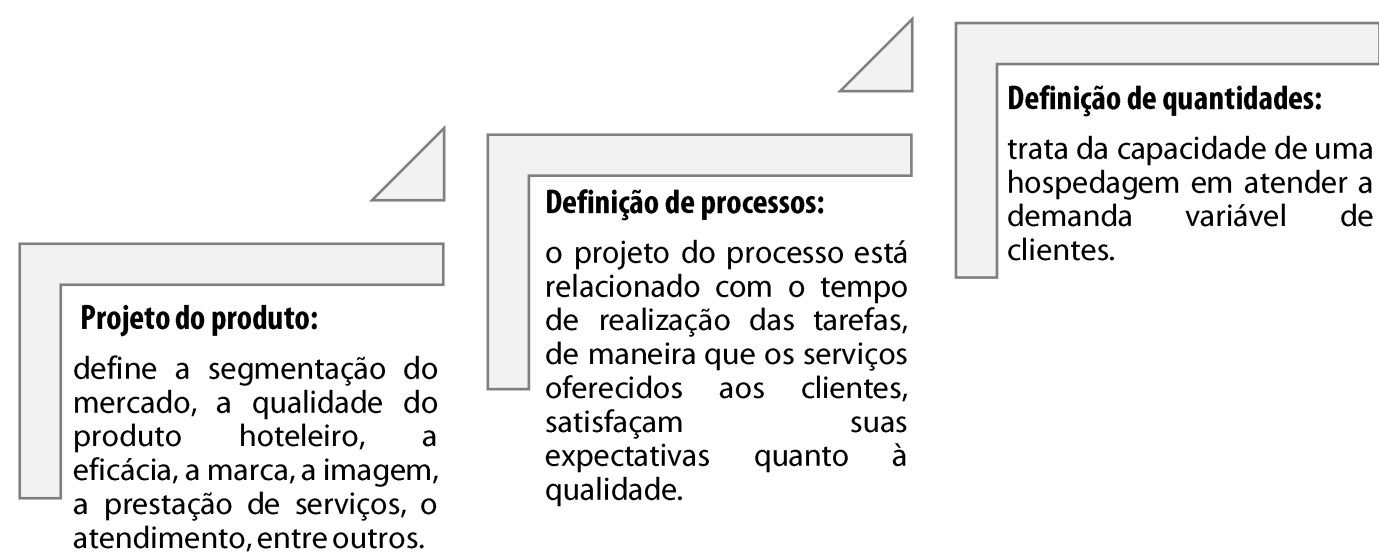

Figura 5. Atividades consideradas para o planejamento das operações de serviços hoteleiros

Fonte: Elaborado pelas autoras (2019)

A programação das operações de serviços hoteleiros, segundo Klement (2000) e Lemos \& Eredmann (1998), compreende as atividades operacionais que uma hospedagem deverá executar para um melhor desempenho: 


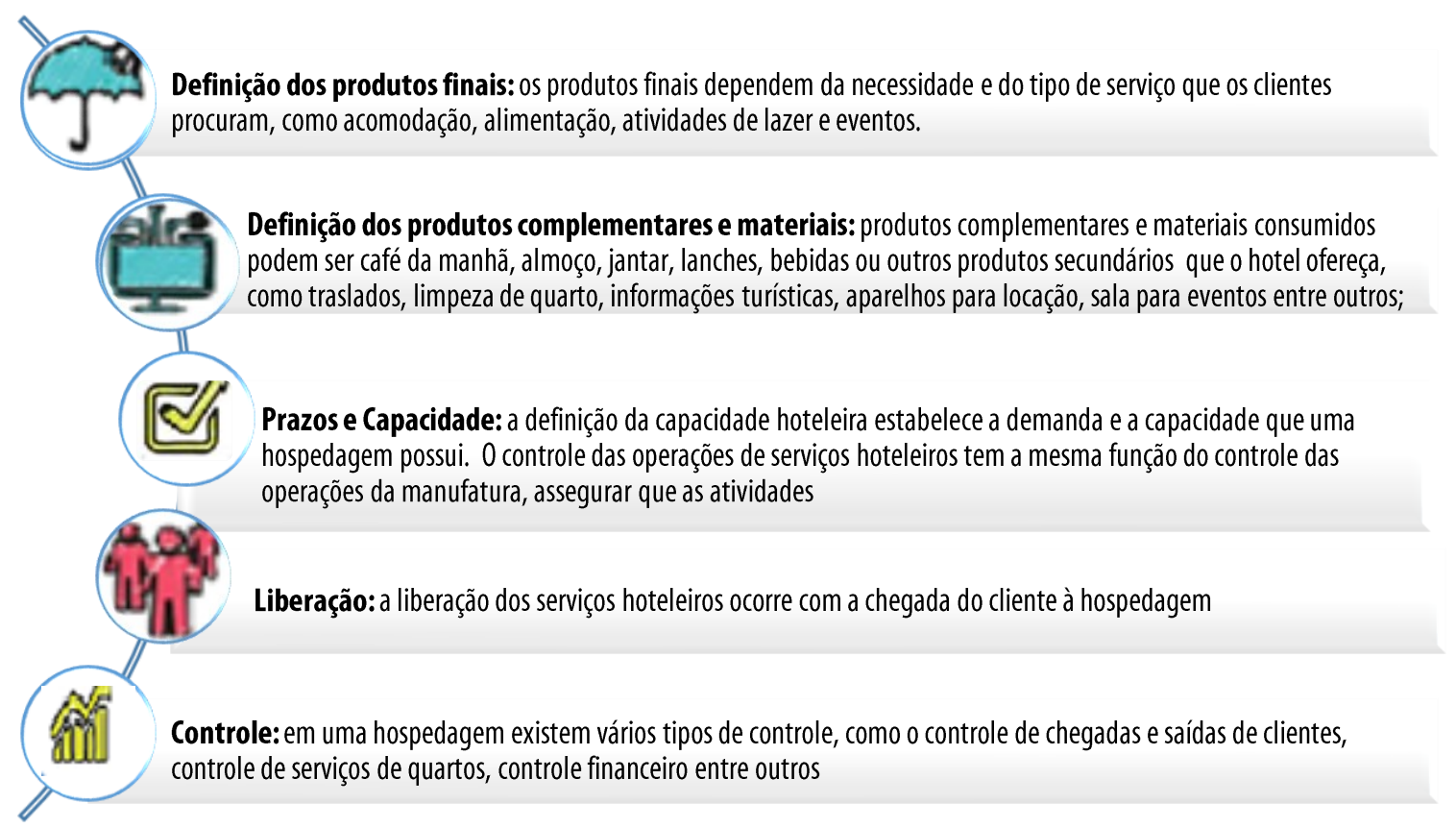

Figura 6. Principais atividades operacionais dos serviços hoteleiros

Fonte: Elaborado pelas autoras (2019)

\subsection{O setor hoteleiro na cidade histórica}

De acordo com Angelo \& Brusadin (2010), o setor hoteleiro na cidade histórica estudada é formado por meios de hospedagem que ocupam casarões do século XVIII. Por motivo de políticas patrimoniais, estes casarões não podem sofrer reformas que descaracterizem o conjunto arquitetônico da cidade. Por esta razão, os meios de hospedagem, localizados no centro histórico da cidade, buscam modernizar as instalações, acompanhando o avanço tecnológico sem, no entanto, descaracterizar as construções, mas, ainda assim satisfazendo as necessidades dos clientes. A maioria dos meios de hospedagem é de base familiar, o que muitas vezes se torna um impedimento para a aplicação de mudanças na estrutura organizacional do empreendimento.

A formação de mão de obra, na maioria dos meios de hospedagem, é um fator que implica, diretamente, no planejamento e na qualidade dos serviços prestados. Apesar da existência de cursos profissionalizantes, de nível técnico e superior na área de hotelaria e turismo, sinalizados na pesquisa de Angelo \& Brusadin (2010), ainda existe, na localidade, carência de formação para as atividades e tecnologias exigidas pelo setor.

A partir do final do ano de 2010, este setor hoteleiro passou a trabalhar em forma de rede organizada por meio da implantação da Associação Brasileira da Indústria de Hotéis (ABIH) - Regional MG. Os objetivos da criação desta regional foram a identificação de oportunidades de mercado e a identificação dos pontos fortes e fracos do setor para possibilitar a definição de estratégias que beneficiassem a hotelaria da região. A regional continua atuando na cidade, mas não conta com a adesão de todos os meios de hospedagem da cidade.

De acordo com pesquisa realizada pelo Ministério do Turismo (MTur) em parceria com o Serviço Brasileiro de Apoio às Micro e Pequenas Empresas (SEBRAE) \& a Fundação Getúlio Vargas (FGV), sobre o Índice de Competitividade do Turismo Nacional (2015), o diferencial da cidade é o fato de ser uma cidade com título de Patrimônio Mundial da UNESCO, além de um calendário de eventos culturais bastante diversificado. Porém, a sazonalidade de visitantes na cidade ainda é bastante percebida pelos empresários do setor hoteleiro. Esta mesma pesquisa revela a ausência de um plano nacional de cultura na cidade, que, se bem desenvolvido, poderia contribuir para uma melhor estruturação do setor hoteleiro.

\section{MATERIAIS E MÉTODOS DA PESQUISA}

Esta pesquisa foi realizada entre os meses de fevereiro 2018 a junho de 2019, no setor de prestação de serviços hoteleiros. Foram selecionados meios de hospedagem em uma localidade pelo fato de ser uma cidade histórica com intensa atividade turística, e significativa oferta de serviços, sobretudo, serviços hoteleiros. 
O método de pesquisa deste estudo teve caráter exploratório e foi desenvolvido por meio de embasamento na literatura de serviços e PCP com a finalidade de oferecer informações fundamentadas sobre o assunto, pois ainda que os conceitos clássicos do PCP sejam bastante estudados no meio acadêmico, os estudos que abordam esses conceitos aplicados ao setor de serviços são, ainda, tímidos.

Um questionário, inspirado nas pesquisas de Guimarães et al. (2009) e Brida \& Santos (2011) foi elaborado, no intuito de realizar análises qualitativas, com algumas observações quantitativas. O questionário foi composto por 53 perguntas, divididas entre perguntas de respostas abertas e fechadas (única resposta e múltiplas respostas). As perguntas foram separadas em nove seções, sendo elas: Seção 1: Informações inicias; Seção 2: Perfil do estabelecimento; Seção 3: Análise quanto ao planejamento dos serviços; Seção 4: Análise do ambiente interno; Seção 5: Análise do ambiente externo; Seção 6: Análise quanto a programação dos serviços; Seção 7: Análise quanto ao acompanhamento e controle dos serviços; Seção 8: Análise ambiental e Seção 9: Avaliação final. As questões tinham como objetivo auxiliar na identificação das características do planejamento e controle de operações de serviços nos meios de hospedagem analisados.

Após elaboração e validação do questionário foram levantados os meios de hospedagem que formariam a população da pesquisa. Realizou-se uma entrevista informal prévia junto à Associação Comercial da cidade, Prefeitura Municipal por meio da Secretaria do Turismo, Indústria e Comércio, Associação Brasileira da Indústria de Hotéis - ABIH e na Internet.

Nesse universo, cerca de 80 meios de hospedagem foram convidados para responder ao questionário por meio de formulário eletrônico e, foram feitas realizadas quatro visitas aos meios de hospedagem do centro da cidade, para coleta de dados de forma presencial. Ao todo, dezessete estabelecimentos aceitaram participar da pesquisa. Os respondentes da pesquisa foram proprietários, gerentes e recepcionistas dos meios de hospedagem de diferentes classificações.

\section{ANÁLISE E DISCUSSÃO DOS RESULTADOS}

A pesquisa bibliográfica realizada para este trabalho indicou algumas possibilidades, para aplicar os conceitos do PCP na gestão das operações de serviços, observando algumas características bem específicas dos serviços. Desta maneira, a pesquisa de campo feita por meio de questionário aplicado e entrevistas informais com gestores e representantes do setor de turismo da cidade. O objetivo do questionário e entrevista foi identificar quais os procedimentos do planejamento e controle são aplicados na gestão das operações de serviços nos meios de hospedagem.

Nos primeiros resultados são apresentados como são classificados os meios de hospedagem na cidade e também qual o porte destes estabelecimentos. Na Figura 8 são apresentadas as porcentagens dos tipos de hospedagem do grupo pesquisado, entre elas estão albergues/ hostels, pousadas, hotéis de três e quatro estrelas. Em relação ao porte dos meios de hospedagem, os estabelecimentos foram classificados quanto ao número de funcionários, em grande, médio, pequeno ou micro. Os meios de hospedagem, que responderam à pesquisa, foram classificados como sendo de micro e pequeno porte, como é apresentado na Figura 9.

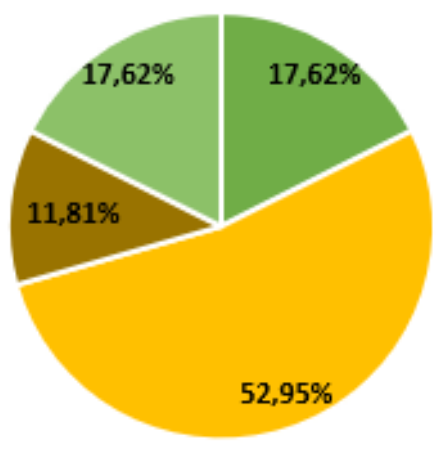

$$
\begin{aligned}
& \text { - Alberg (hostel) } \\
& \text { - Pensão } \\
& \text { - Pousada } \\
& \text { - Hotel } 1 \text { estrela } \\
& \text { - Hotel } 2 \text { estrela } \\
& \text { - Hotel } 3 \text { estrela } \\
& \text { - Hotel } 4 \text { estrela } \\
& \text { - Hotel } 5 \text { estrela }
\end{aligned}
$$

Figura 7. Classificação dos meios de hospedagem

Fonte: Elaborado pelas autoras (2019) 

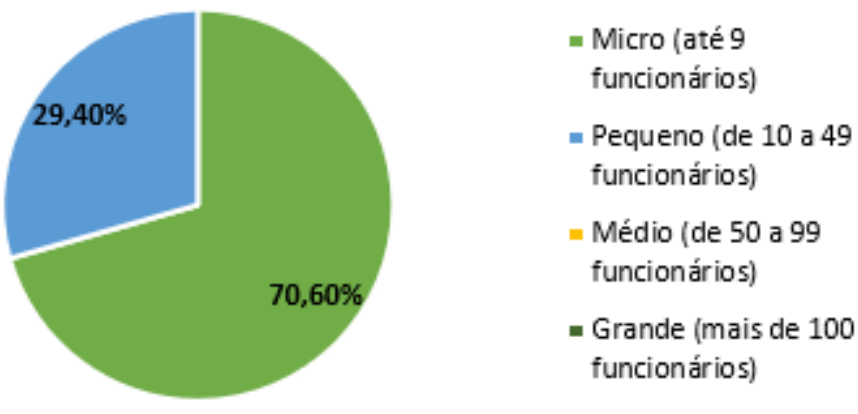

Figura 8. Classificação dos meios de hospedagem quanto ao número de funcionários Fonte: Elaborado pelas autoras (2019)

Conforme observado na revisão da literatura, o produto de uma hospedagem é, na verdade, um serviço, portanto, intangível, de consumo simultâneo e não estocável. Desta maneira, o projeto do serviço segue os mesmos princípios do projeto de produto da manufatura. Porém, em serviços os gestores lidam com imprevisibilidade e variabilidade de demanda e, principalmente, com pessoas, por isso, o projeto de serviços deve ser planejado de forma eficaz, atentando para o segmento de mercado no qual está inserido de forma a prestar um serviço que satisfaça o cliente.

Os serviços oferecidos pelo setor hoteleiro da cidade procuram atender aos mais diversos perfis de clientes. Por se tratar de uma cidade histórica e patrimônio da humanidade, a presença de visitantes de todo - Brasil, principalmente da região sudeste, e, também é bastante frequente, estrangeiros da França, da Inglaterra, da Alemanha e dos Estados Unidos. Na Figura 10, são mostradas as localidades de origem da maioria dos clientes desses meios de hospedagem e a porcentagem de visitantes por regiões do país e de estrangeiros.
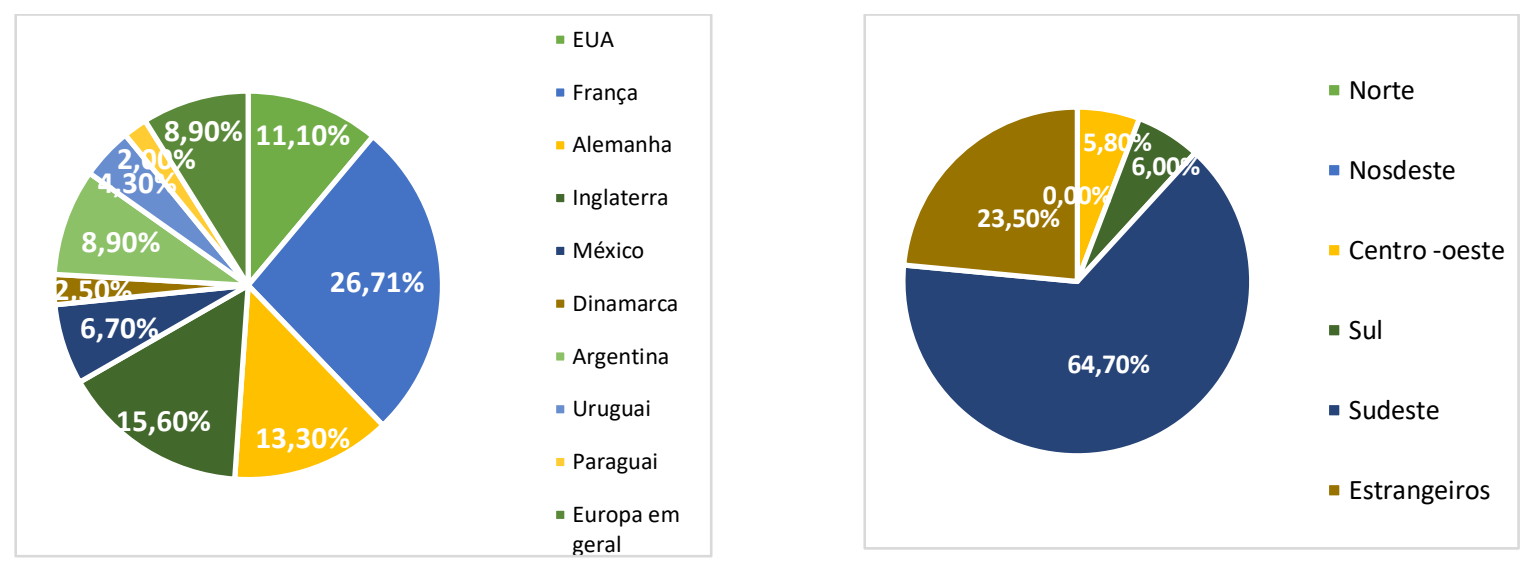

Figura 9. Origem dos visitantes e região visitadas

Fonte: Elaborado pelas autoras (2019)

A cidade estudada tem um calendário de eventos culturais como carnaval, semana santa, festival de inverno, festival de jazz, festivais gastronômicos entre outros como a realização de feiras, congressos e eventos acadêmicos, que também atraem bastante visitantes.

Deste modo, a pesquisa identificou o perfil dos visitantes que se hospedam na cidade. Estes são, em sua maioria, casais e famílias, e em menor quantidade os estudantes, mochileiros e congressistas, o que pode ser observado na Figura 11. As respostas aos questionários revelaram também, que a média de dias que os clientes ficam hospedados na cidade é de três dias, veja a Figura 12.

Um ponto a observar em relação ao projeto do produto (serviço), é que existem outras cidades históricas próximas à localidade de estudo. Este fato pode sinalizar uma disputa entre os serviços hoteleiros, pois, vários dos respondentes relataram que muitas das vezes os visitantes apenas passam o dia na cidade, mas não chegam a utilizar os serviços de hospedagem. Uma das principais reclamações identificadas na pesquisa foi a necessidade de maior interação entre o setor hoteleiro e a administração pública, criando 
parcerias para melhorar a promoção dos eventos culturais, assim como, a criação ou o resgate de antigos eventos, de maneira a aproveitar o potencial turístico da cidade e como forma de incentivo ao setor hoteleiro.

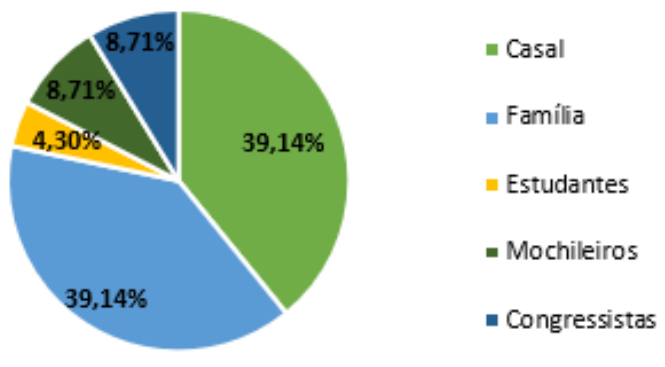

Figura 10. Perfil dos visitantes

Fonte: Elaborado pelas autoras (2019)

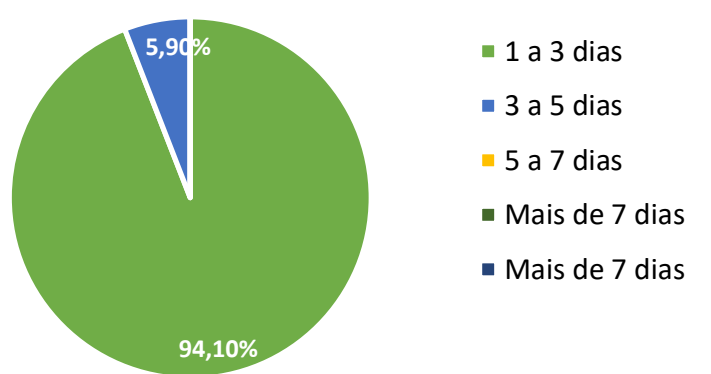

Figura 11. Média de dias que os visitantes ficam hospedados

Fonte: Elaborado pelas autoras (2019)

O processo de serviço apresenta semelhança com o processo do produto. O controle do tempo e o planejamento das operações de retaguarda, nos meios de hospedagem analisados, como por exemplo, as atividades de lavanderia, limpeza, manutenção predial, manutenção elétrica, manutenção de equipamentos, compras de suprimentos e compra de produtos para estoque (toalhas, roupa de cama, e outros), são melhor estimados em comparação a operações de linha de frente, como é mostrado na Figura 13. Estas são operações mais previsíveis e padronizáveis uma vez que não são de contato direto como o cliente. Já para as operações de linha de frente, como recepção e serviço de quarto, por exemplo, têm seu tempo estimado empiricamente por apresentarem bastante variabilidade.

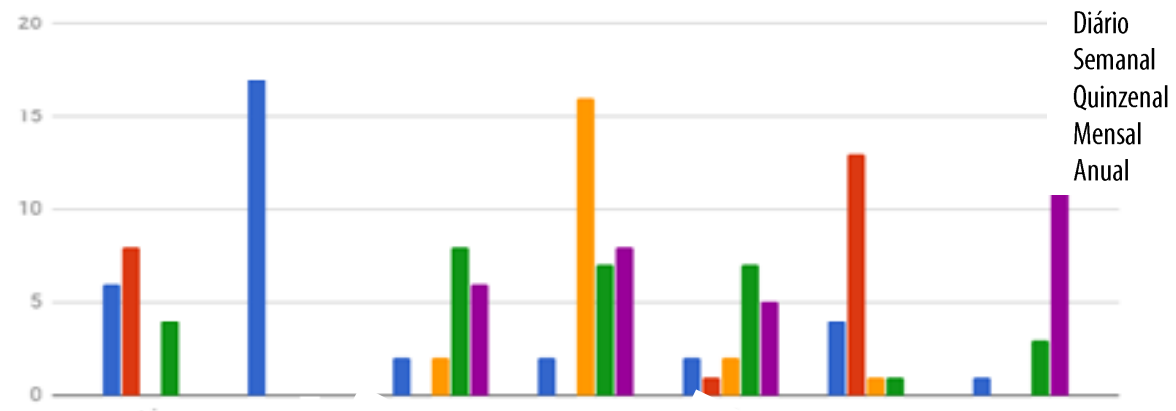

Lavanderia

Limpeza

Manutençãal lanutençã®anutenção d elétrica predial

equipamenţ

suprimento
Compra de produtos para estoque predial 
De acordo com os gestores, os funcionários, dos meios de hospedagem analisadas conhecem bem as atividades do processo de serviços, o que reduz atrasos e esperas por parte do cliente, Figura 14. Mas, a reciclagem dos conhecimentos para a atividade diária não é realizada com relativa frequência, como aponta a Figura 15. Este é um fator a ser trabalhado e melhorado pelos gestores dos meios de hospedagem analisadas, pois o preparo dos funcionários, tanto nas operações de linha de frente quanto nas de retaguarda influencia diretamente na percepção do cliente em relação a qualidade dos serviços prestados.

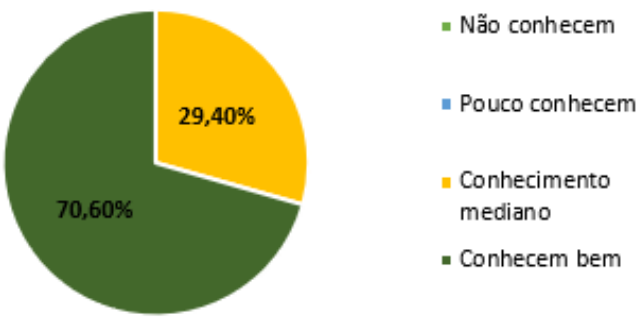

Figura 13. Conhecimento das operações pelos funcionários

Fonte: Elaborado pelas autoras (2019)

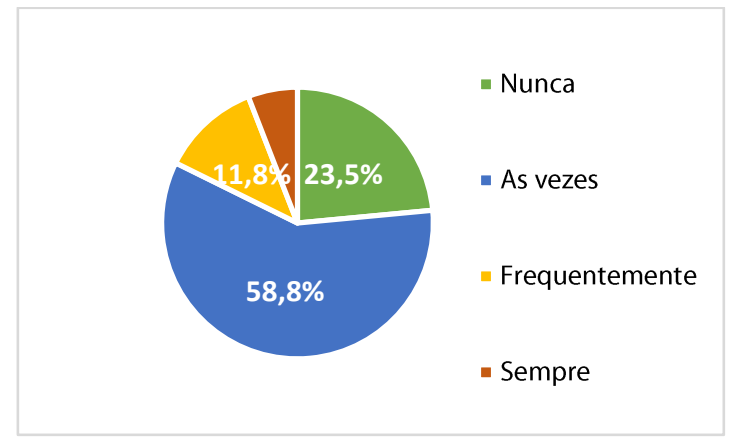

Figura 14. Frequência de treinamento dos

funcionários

Fonte: Elaborado pelas autoras (2019)

Quanto à demanda de hóspedes, observou-se, por meio da análise do questionário, que a previsão da demanda é feita empiricamente, ou seja, por meio de observação dos gestores ao efeito sazonal da demanda de visitantes na cidade. Na Figura 16, pode ser identificado que, o planejamento das atividades é realizado, também, empiricamente, ou seja, cada estabelecimento planeja suas atividades em períodos bastante distintos umas das outras. O planejamento das operações é realizado, geralmente, por uma pessoa apenas, pelo proprietário em pequenos estabelecimentos ou pelo gerente, no caso de meios de hospedagem maiores.
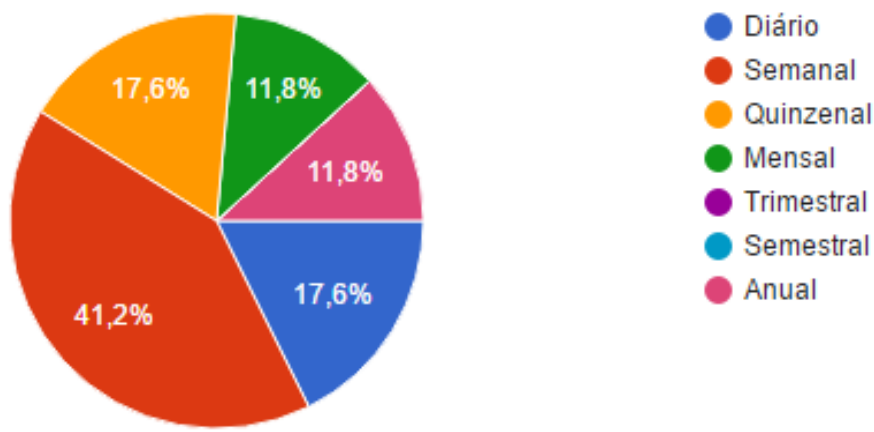

Figura 15. Planejamento das atividades com base na demanda

Fonte: Elaborado pelas autoras (2019)

Os responsáveis pelos meios de hospedagem relataram, em sua maioria, que os períodos de maior demanda por serviços do setor hoteleiro na cidade são os grandes feriados nacionais (carnaval, semana santa, etc.) e os meses de junho e julho quando ocorre as férias escolares, o festival de inverno e o festival de cinema.

Em relação a programação das operações de serviços, alguns dos meios de hospedagem trabalham com sistema informatizado de gestão e coleta de informações dos clientes, o que gera um banco de dados que pode auxiliar na tomada de decisões e planejamentos futuros, porém, outras não fazem uso de recursos informatizados para este fim, essas geralmente utilizam fichas de cadastro, como pode ser observado na Figura 17.

A pesquisa identificou que a utilização de softwares aplicados no PCP na manufatura, como por exemplo, o MRP e ERP, não se aplicam ao setor hoteleiro analisado, por se tratar de empresas pequenas, cuja capacidade e complexidade das operações, além dos custos significativos de aquisição e implementação destes softwares não justificaria o investimento. A maioria dos meios de hospedagem participantes do estudo apresentam cerca de $10 \%$ de suas atividades informatizadas, como é mostrado na Figura 18, as hospedagens, que utilizam algum sistema de informação, fazem uso de sistemas voltados para o setor de serviços hoteleiros. 


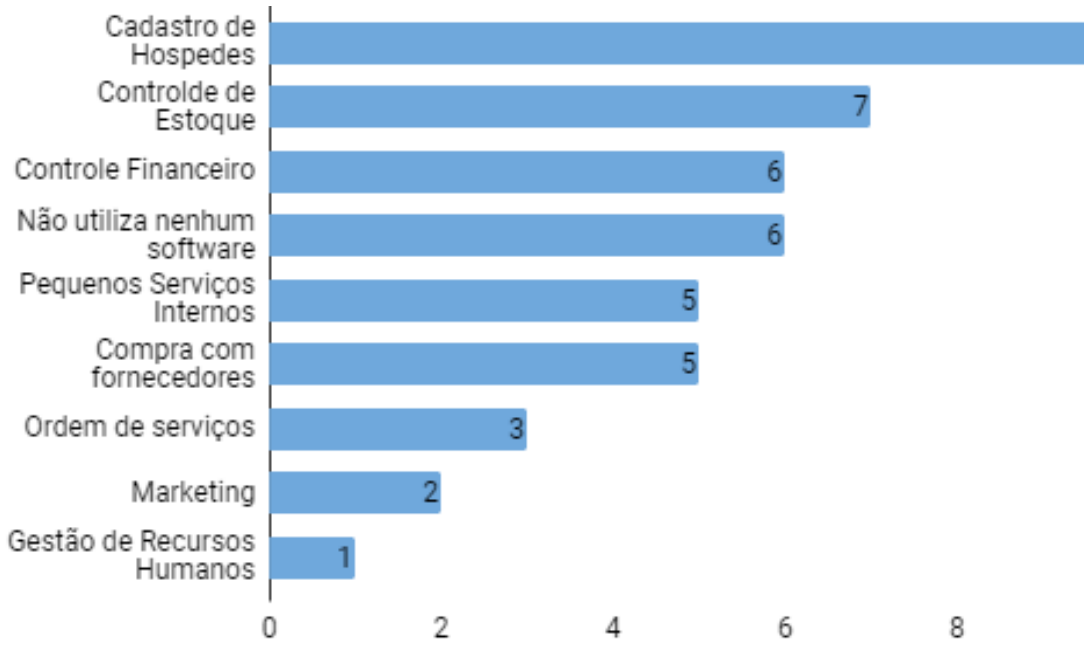

Figura 16. Recursos informatizados para programação e controle das operações Fonte: Elaborado pelas autoras (2019)

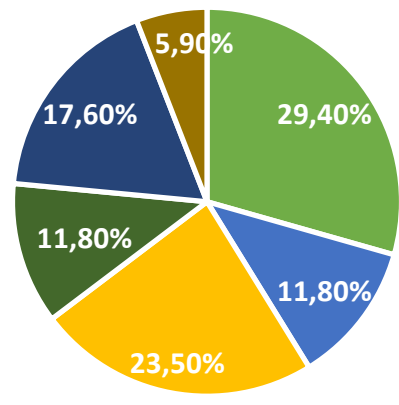
Abaixo de $10 \%$
- $10 \%$ a $20 \%$
- $20 \%$ a $40 \%$
$40 \%$ a $60 \%$
- $60 \%$ a $80 \%$
- Mais de $80 \%$

\section{Figura 17. Porcentagem de atividades informatizadas}

Fonte: Elaborado pelas autoras (2019)

A programação das operações de serviços envolve, ainda, a definição de produtos finais, que no caso do setor hoteleiro é o serviço de acomodação. Além da acomodação, alguns meios de hospedagem oferecem, também, serviços complementares como café da manhã, estacionamento, espaço para realização de eventos, internet, entre outros. Os serviços oferecidos são apresentados na Figura 19.

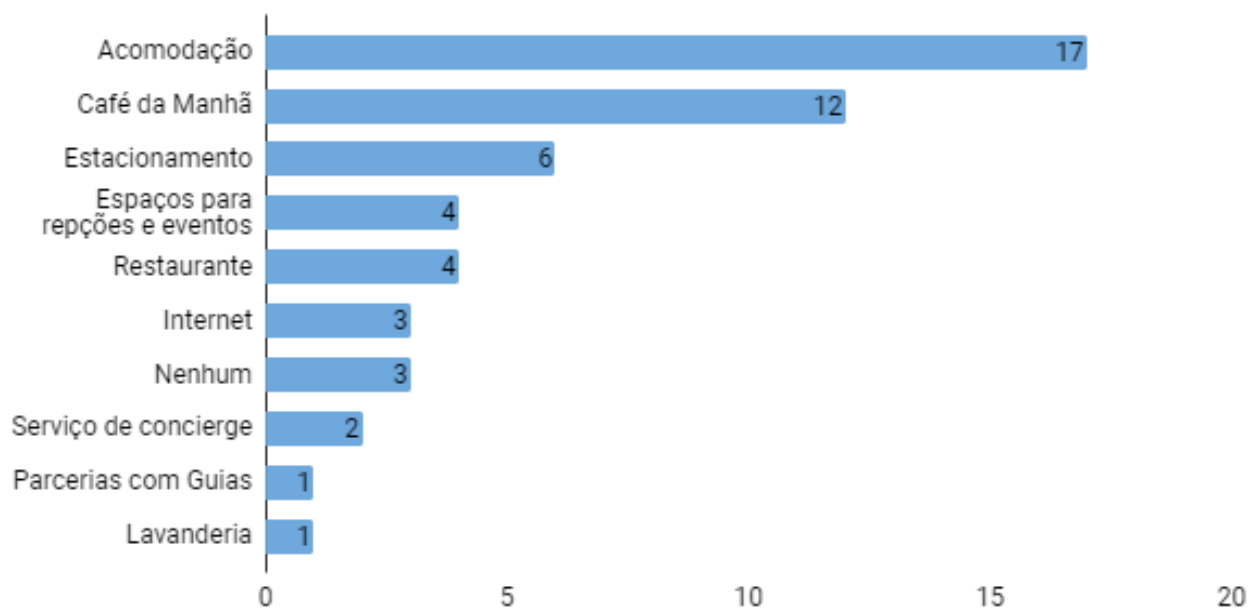

Figura 18. Serviços complementares oferecidos pelos meios de hospedagem

Fonte: Elaborado pelas autoras (2019) 
A maioria dos meios de hospedagem trabalha com reservas, que podem ser realizadas pelo site ou telefone de contato da hospedagem, ou, mesmo, por meio de sites de reservas. Nesse contexto, é possível observar como o marketing exerce influência na segmentação de mercado dos meios de hospedagem, assim como, é bastante relevante para a realização de uma boa gestão das operações. A comunicação com os clientes pode ser utilizada como mecanismos de divulgação do serviço, o que pode ser observado nas Figuras 20 e 21.

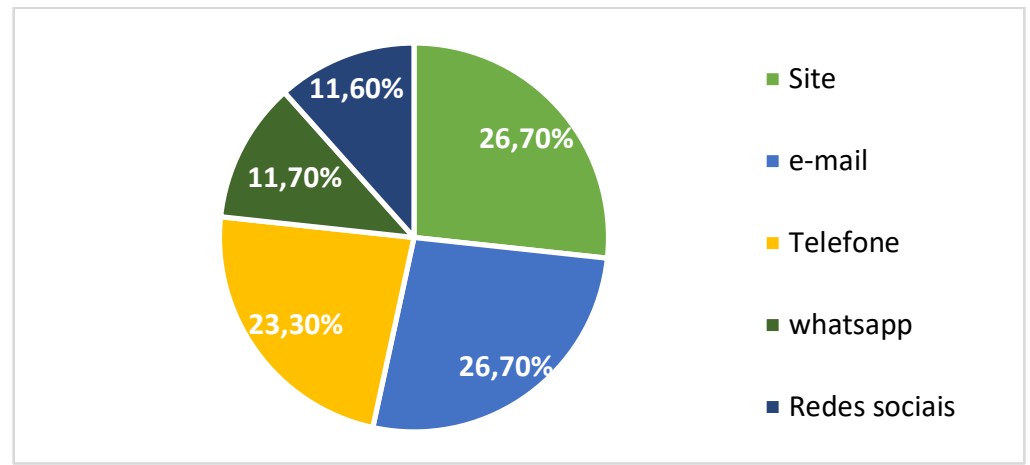

Figura 21. Meios de comunicação com os clientes

Fonte: Elaborado pelos autores (2019).

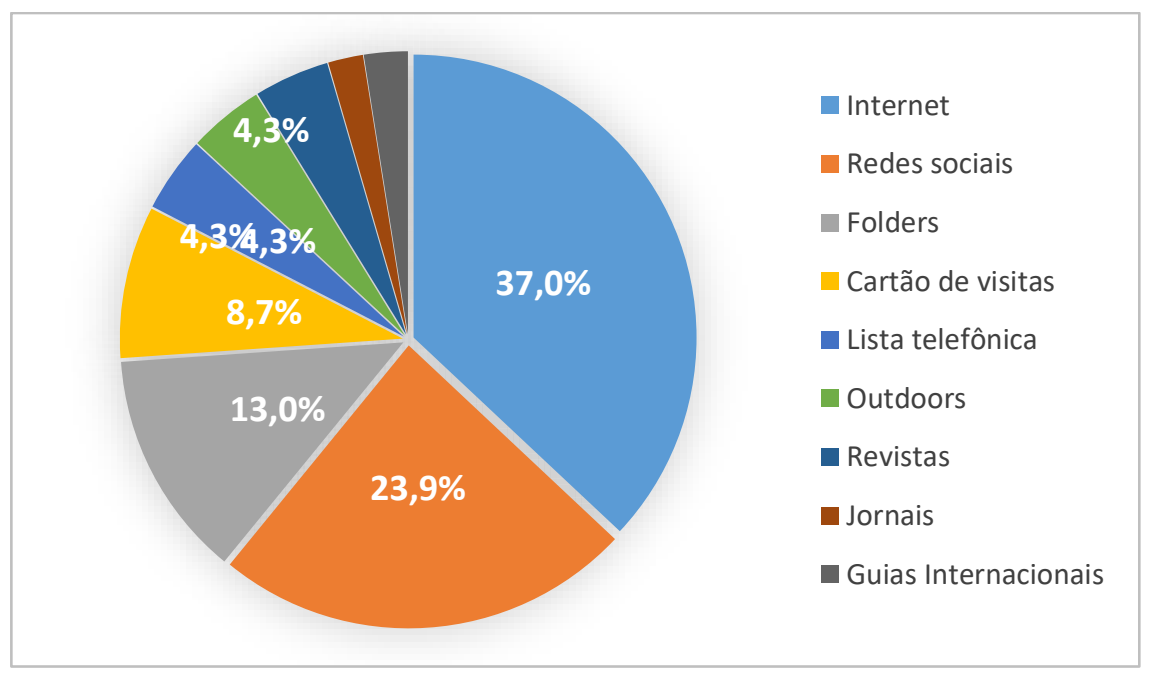

Figura 22. Meios de divulgação da empresa - marketing

Fonte: Elaborado pelos autores (2019).

É possível observar que o marketing auxilia na divulgação dos meios de hospedagem. Ele também pode trazer informações para o planejamento das operações e análise da capacidade. A capacidade dos serviços hoteleiros, além de estar relacionada com o porte do meio de hospedagem, depende também do atendimento, de forma a satisfazer a demanda e as necessidades dos clientes.

No contexto analisado, os meios de hospedagem não apresentaram qualquer problema em atender a demanda dos clientes. Porém, alguns gestores relataram a necessidade de outros serviços de apoio na cidade, serviços estes que, juntamente com a hospedagem, constituiriam a cadeia de suprimentos do setor hoteleiro da região, como fornecedores de produtos para o café da manhã, lavanderias, serviços de internet e outros similares. Ainda, em relação à capacidade, relataram também, a necessidade de planejamentos para a capacidade ociosa em períodos de baixa temporada.

Quanto à definição de materiais, a quantidade de material necessária para as atividades do setor é definida empiricamente pelos gestores dos meios de hospedagem de menor porte, como os hostels e pequenas pousadas, enquanto que os hotéis de maior porte possuem um planejamento mais elaborado da necessidade de materiais, mas não necessariamente fazem uso de softwares de gestão de materiais. A pesquisa identificou que a quantidade de material é analisada com base na percepção de necessidades. Na maioria dos meios de hospedagem, não há um setor específico de compras, mas isso se deve, principalmente, ao porte dos estabelecimentos, o que, de certa forma, não implica mesmo na necessidade de um setor específico de compras, mas também não minimiza a necessidade de planejamento da atividade. 
Desta forma, como as atividades de compra, o controle do estoque de materiais é feito pelos gestores dos meios de hospedagem. Estas duas atividades se assemelham muito às atividades de compra de suprimento e controle de estoque na manufatura, porém em escala menor. Com a realização da análise destas atividades foi possível perceber como algumas das operações de serviços são semelhantes às operações de manufatura, conforme descreve a literatura. Compras, quantidade de material e controle de estoque, são atividades nas quais os gestores trabalham com produtos, mas que fazem parte da oferta de um serviço. Então, é possível perceber a interação entre as operações de bens e serviços mostrada na literatura, como um "feixe", no qual serviços e produtos complementam um ao outro em proporções distintas.

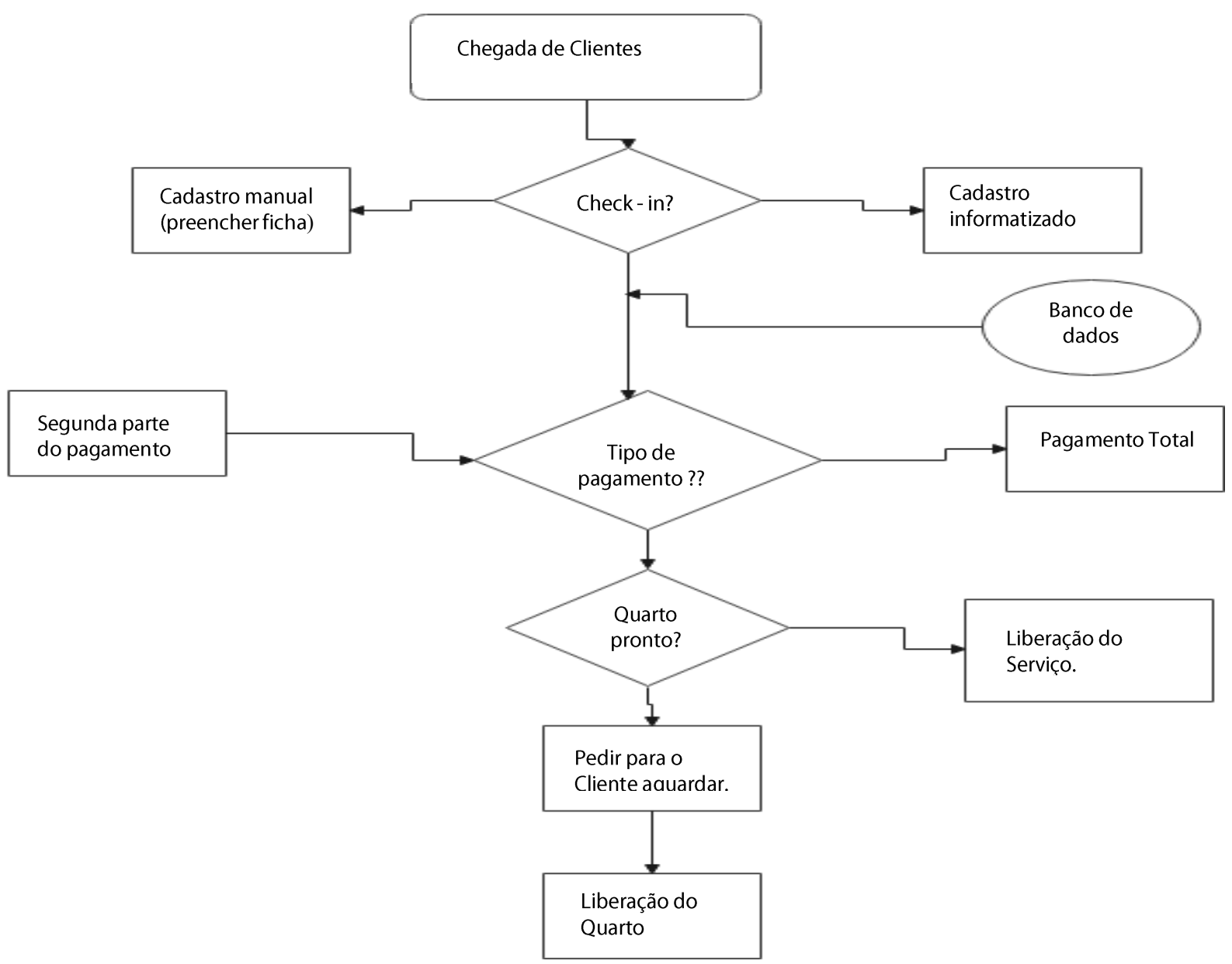

Figura 19. Fluxograma das atividades de liberação dos serviços na chegada do cliente

Fonte: Elaborado pelas autoras (2019)

Finalmente, quanto ao controle das operações dos serviços hoteleiros analisados na cidade, identificaram-se as seguintes etapas que podem ser observadas no fluxograma da Figura 22:

- A liberação dos serviços é iniciada com a chegada do cliente para fazer o check-in;

- Em seguida, o cliente preenche o cadastro na recepção.

- Em alguns meios de hospedagem, este serviço é informatizado e, por isso, muitas vezes mais rápido e com coleta de maior número de informações sobre o cliente;

- Em outros meios de hospedagem, o próprio cliente preenche uma ficha de cadastro impressa.

- Logo após, o cliente realiza o pagamento do serviço. Esse pagamento é feito integralmente, ou o cliente paga a segunda metade da reserva, caso a primeira parte do pagamento já tenha sido solicitada no ato da reserva, conforme a política da hospedagem.

- Então, o cliente recebe a chave de quarto, o que representa a liberação do serviço. As atividades, aqui listadas.

Vale ressaltar que a liberação dos serviços depende de algumas operações de retaguarda como a limpeza do quarto, por isso, a importância do planejamento e controle de todas as operações envolvidas no 
serviço para que as expectativas dos clientes sejam satisfeitas, o que gera impactos diretos na percepção do cliente quanto à qualidade dos serviços.

Em relação ao controle das operações de serviços, foi possível observar que não é efetuado, na maioria dos meios de hospedagem, um controle bem estruturado das atividades. A maioria dos estabelecimentos trabalha com o método de supervisão direta de seus funcionários. Alguns proprietários de meios de hospedagem realizam eles mesmos, as atividades de recepção, de compra de material e de controle de estoque. Já os resultados das operações de serviços, são verificados em sua maioria semestralmente, como visualizado na Figura 23.

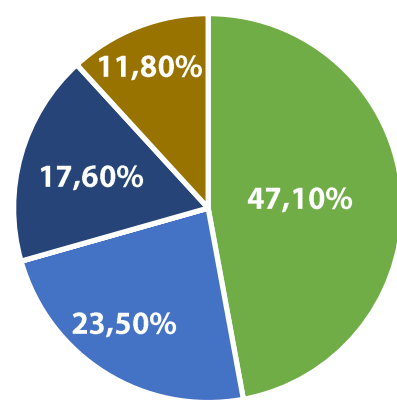

$$
\begin{aligned}
& \text { - Semestral } \\
& \text { - Anual } \\
& \text { - A cada dis anos } \\
& \text { - Mais de dois anos } \\
& \text { - Não se aplica } \\
& \text { - Semanal }
\end{aligned}
$$

Figura 20. Frequência de acompanhamento dos resultados dos planejamentos para os meios de hospedagem

Fonte: Elaborado pelas autoras (2019)

De maneira geral, foi possível observar, com esta pesquisa, que um dos pontos de melhoria das operações de serviços no setor hoteleiro na cidade é um maior investimento na atividade de planejamento estratégico para as operações. O planejamento e controle das operações de serviços hoteleiros na maioria dos meios de hospedagem ocorrem de maneira empírica. Conceitos como os de missão, visão e valor não estão presentes na maioria dos meios de hospedagem analisadas, como apontam as Figuras 24, 25 e 26.

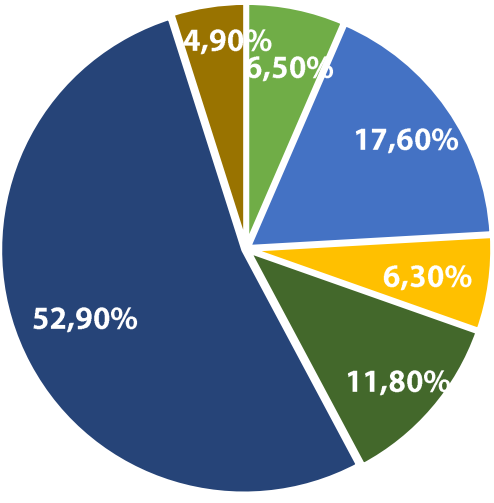
Semestral
- Anual
$\square$ A cada dois anos
- Mais que dois anos
- Não se aplica
- Sempre

Figura 21. Ajuste da missão

Fonte: Elaborado pelas autoras (2019) 


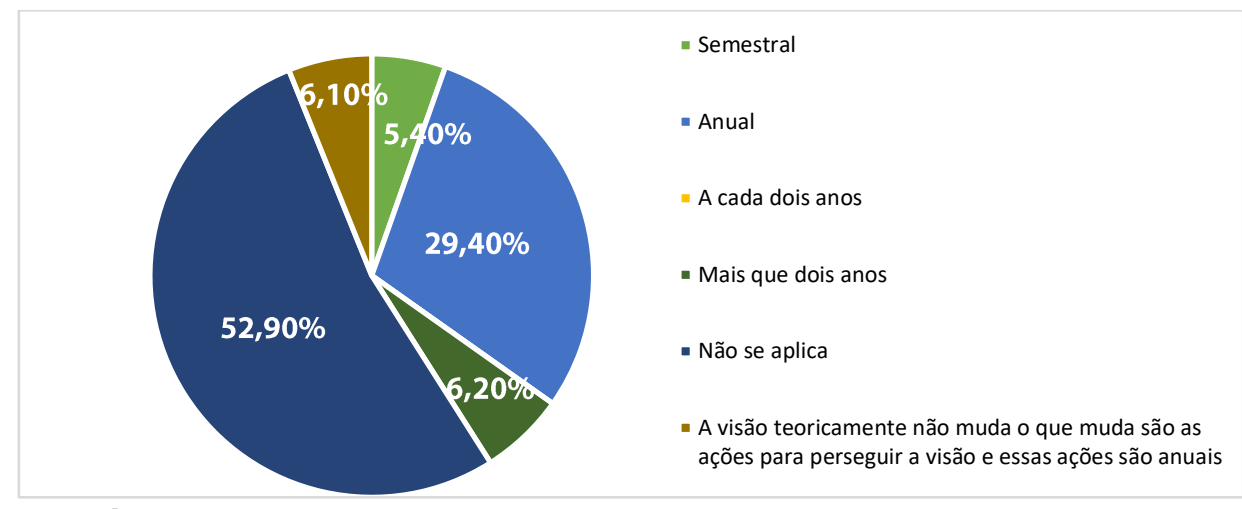

Figura 22. Ajuste da visão

Fonte: Elaborado pelas autoras (2019)

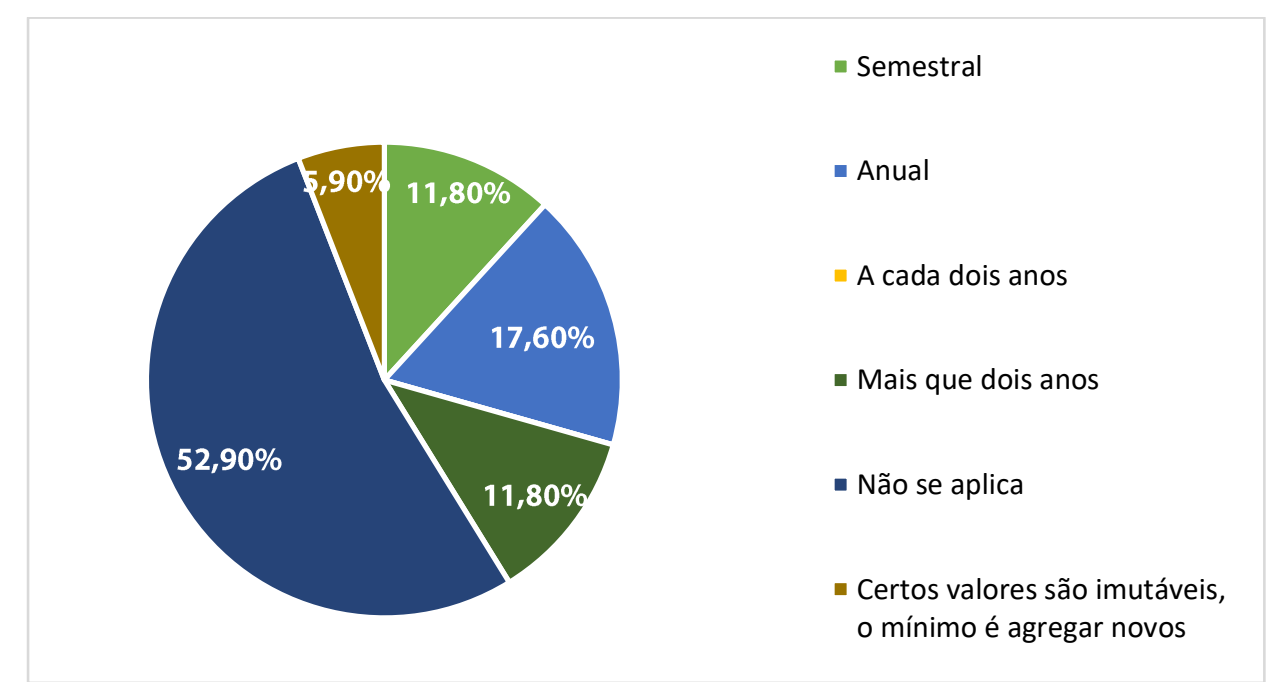

Figura 23. Ajuste dos valores

Fonte: Elaborado pelas autoras (2019)

\section{CONSIDERAÇÕES FINAIS}

Nesta pesquisa foi investigada a intensidade da aplicação do PCP em serviços de hotelaria, com base em revisão bibliográfica, que apontou como este assunto vem sendo abordado no decorrer dos anos. Também foi realizada, por meio de entrevistas e um questionário, uma análise prática da aplicação do planejamento e controle em serviços, especificamente, no setor hoteleiros em uma cidade histórica. Deste modo, a pesquisa trouxe contribuições com informações para pesquisadores e gestores que estejam investigando ou atuando no planejamento e controle de operações de serviços.

A pesquisa evidenciou a aplicabilidade dos conceitos clássicos do PCP em serviços, identificou na literatura e na pesquisa de campo a necessidade de adaptações do sistema de PCP da manufatura para sua aplicação em serviços, devido às características específicas dos serviços. A intensa participação do cliente nas operações de serviços foi um ponto de atenção, pois sinaliza a importância da boa gestão das operações, atentando sempre para as percepções e satisfação do cliente. Vale ressaltar que, uma das características mais observadas atualmente no cliente é a constante exigência de melhores serviços. A percepção quanto a um serviço de qualidade está diretamente ligada a gestão das operações desses serviços, ou seja, é notório quando as operações de serviços são executadas com métodos de planejamento e controle adequados.

Em relação ao setor hoteleiro na cidade analisada, notou-se a necessidade, na maioria dos meios de hospedagem, de uma elaboração e implantação do planejamento estratégico das operações. Este mecanismo poderá auxiliar aos gestores na identificação e resolução de problemas, previsão de demanda, reação rápida em relação as incertezas de mercado e identificação e elaboração de possibilidades de melhoria nas atividades. Em muitos dos meios de hospedagem estudadas, o planejamento e o controle das operações são realizados de modo empírico, ou seja, a gestão das operações de serviços é feita com base em experiências anteriores ou mesmo por meio da tentativa e erro. Este fato, pode trazer riscos, inseguranças e muitos desafios inesperados aos gestores, principalmente no que tange a situações de alta demanda. 
Considerando que o objetivo desta pesquisa foi analisar a aplicação do PCP nos serviços hoteleiros em uma cidade histórica, a elaboração de estudos sobre o planejamento estratégico das operações das empresas do setor de serviços hoteleiros, seria uma possibilidade de continuidade deste trabalho. Como outra possibilidade de desdobramentos desta pesquisa, sugere-se a análise do PCP aplicado a outros setores de serviços na cidade, ou mesmo, análises mais especificas como o estudo da previsão de serviços para a cidade e analise de uma rede integrada de serviços, visando maior tempo de estadia dos turistas. Novos estudos poderão contribuir significativamente para uma gestão eficiente das operações de serviços, bem como, a possibilidade de abrir espaços de discussão e novas metodologias de gestão neste setor.

\section{REFERÊNCIAS}

Angelo, F. D., \& Brusadin, L. B. (2010). Interfaces dos Serviços Hoteleiros de Ouro Preto- MG. Revista Anagrama: Revista Científica Interdisciplinar da Graduação, 4, São Paulo: Cidade Universitária.

Avila, S. R. S. A., \& Avila, M. L. (2001). Satisfação de usuários: Uma análise dos serviços prestados por uma cooperativa médica. Administração On Line, 2(4).

Bowen, J., \& Ford, R. C. (2002). Managing service organizations: Does having a "thing" make a difference?. Journal of management, , pp. 28(3), 447-469.

Brida, M. de, \& Santos, J. N. (2011). O Alinhamento entre a Estratégia e as Competências Organizacionais: o caso de uma empresa nacional líder do segmento de revestimentos cerâmico. Revista de Ciências da Administração, 13(31).

Brito, T. C., \& Santos, L. C. (2019). Aplicabilidade de práticas de produção enxuta em operações de serviços: uma análise pela perspectiva de olume e variedade. Exacta, 17 (3).

Castelli, G. (1992). Administração hoteleira. Porto Alegre: Suliani.

Chase, R. B., Jacobe, F. R. \& Aquilano, N. T. (2006). Administração da Produção para a Vantagem Competitiva. Porto Alegre: Bookman.

Corrêa, H. L., \& Corrêa, C. A. (2008). Administração de Produção e Operações: Manufatura e serviços: uma abordagem estratégica. São Paulo: Atlas.

Costa, O. (2017). Como a Internet das Coisas vai "Servicificar" os Produtos e Mudar sua Vida? Disponível em: https://www.linkedin.com/pulse/como-internet-das-coisas-vai-servicificar-os-produtos-costa

Davis, M. M., Aquilano, N. J., \& Chase, R. B. (2001). Fundamentos da Administração da Produção. Porto Alegre: Bookman.

Dieese., D. I. (2013). Estudo do Setor Hoteleiro. São Paulo: Confederação Nacional dos Trabalhadores no Comércio e Seviços da CUT.

Fitzsimmons, J. A., \& Fitzsimmons, M. J. (2000). Administração de serviços: operações, estratégia e tecnologia de informação. Porto Alegre: Bookman.

Gianesi, I. G. N., \& Correa, H. L. (1994). Administração estratégica de serviços: operações para a satisfação do cliente. São Paulo: Atlas.

Graeml, K. S., Kloster, N. J. A., Costa, L. C., \& Mazia, R. F. (2000). Considerações estratégicas sobre a gestão de um hotel de lazer. In: Anais do Encontro Nacional de Engenharia de Produção, XX. São Paulo: ABEPRO.

Guasso, I. (2009). Os Serviços e a Empresa Hoteleira: um estudo de caso do Cristal Palace (Trabalho de Conclusão de Curso, Centro Universitário Católico). Disponível em: http://www.unisalesiano.edu.br/biblioteca/monografias/48866.pdf 
Guimarães, C. C., Silveira, J. Q., Yusim, L. A., Motta, O. M., \& Quelhas, O. L. G. (2009). Análise de Modelos e Práticas de Planejamento e Controle da Produção na Indústria Gráfica. Revista Carioca de Produção RECAP.

Guimarães, I. F. (2010). Estudo Sobre Qualidade e Eficiência na Gestão Pública (Trabalho de Conclusão de Curso, Universidade Federal de Ouro Preto).

Heizer, J., \& Render, B. (2001). Administração de operações: Bens e Serviços. Rio de Janeiro: LTC Editora.

Hospitality Group (2019). Hotelaria em Números - Brasil 2019. Disponível em: http://fohb.com.br/wpcontent/uploads/2019/08/Hotelaria-em-n\%C3\%BAmeros-2019.pdf.

IBGE (2018). Brasil em Síntese: serviços. Disponível em: http://brasilemsintese.ibge.gov.br/servicos.html.

Johnston, R., \& Clark, G. (2002). Administração de operações de serviços. São Paulo: Atlas.

Klement, C. F. (2000). Complexidade no Sistema de Produção de Serviços: Um Estudo de Caso no Setor Hoteleiro. (Dissertação de mestrado, Universidade Federal de Santa Catarina). Disponível em: https://repositorio.ufsc.br/xmlui/handle/123456789/78976

Knupp, M. E. (2012). A Classificação de Meios de Hospedagem no Brasil. TURYDES -Revista de Investigación en turismo y Desarrollo Local, 5(13).

Lemos, R. N., \& Erdmann, R. H. (1998). O Conceito de Planejamento e Controle da Produção e o Serviço Hoteleiro. In: Anais do Encontro Nacional de Engenharia de Produção, XVIII, Niterói - RJ. Niterói: Abepro.

Lovelock, Christopher, Wirtz, Jock en, \& Henzo, Miguel Angelo. (2011). Marketing de serviços: pessoas, tecnologia e estratégia. 7 ed. São Paulo: Pearson Prentice Hall.

Lustosa, L., Mesquita, M. A., \& Quelhas, O. (2008). Planejamento e controle da produção. Rio de Janeiro: Elsevier.

Mello, G., \& Goldenstein, M. (2010). Perspectivas da Hotelaria no Brasil. Turismo - BNDES Setorial, 5-43.

Ministério da Indústria Comércio Exterior e Serviços (2017). A importância do setor terciário. Disponível em: http://www.mdic.gov.br/comercio-servicos/a-secretaria-de-comercio-e-servicos-scs/402-a-importanciado-setor-terciario

Moreira, R. (06 de setembro de 2017). Os serviços em 2017. Disponível em: http://economiadeservicos.com/tag/pib/

Pereira, F. F., \& Coutinho, H. R. M. (2007). Hotelaria: da Era Antiga aos Dias Atuais. Revista Eletrônica Aboré, 3, p. 1-16.

Rodrigues, S. B., Barbosa, F. V., Luz, T. R., \& Kilimnik, Z. M. (1986). Tecnologia de informação nos serviços: o impacto na configuração do trabalho. Revista de administração de empresas, 26(1), p. 43-56.

Santos, L. C., Varvakis, G., Gohr, C. F. (2004). Por que a estratégia de operações de serviços deveriam ser diferentes? Em busca de um modelo conceitual. In: Anais do Encontro Nacional de Engenharia de Produção-ENEGEP, XXIV, Florianópolis - SC. Florianópolis-SC: Abepro.

Soltani, E., Barnes, B., Syed, J., \& Liao, Y. Y. (2012). Does management's approach impede service quality? Production Planning \& Control, 523-540.

Turismo, M. D. (junho de 02 de 2011). Fonte: Cartilha de Orientação Básica 1: Sistema Brasileiro de Classificação de Meios de Hospedagem. : Disponível em:

http://www.classificacao.turismo.gov.br/MTUR-classificacao/mtur-site/downloadCartilha.action?tipo=1

Turismo, M. d. (06 de março de 2020). Turismo movimentou R\$ 238,6 bilhões no Brasil em 2019, aumento de 2,2\%. Fonte: Ultimas Notícias: Disponivel em: http://www.turismo.gov.br/\%C3\%BAltimas- 
not\%C3\%ADcias/13379-turismo-movimentou-r\$-238,6-bilh\%C3\%B5es-no-brasil-em-2019,-aumentode-2,2.html

Vargo, S. L., \& Lusch, R. F. . (2004). The four service marketing myths: remnants of a goods-based, manufacturing model. Journal of service research, pp. 6(4), 324-335. 